\title{
LA-UR-21-22645
}

Approved for public release; distribution is unlimited.

Title: $\quad$ Structured Membrane-electrode Interface for Highly Efficient PEM Fuel Cell

Author(s): $\quad$ Yang, Gaoqiang

Intended for: Interview presentation

Issued: 
Disclaimer:

Los Alamos National Laboratory, an affirmative action/equal opportunity employer, is operated by Triad National Security, LLC for the National Nuclear Security Administration of U.S. Department of Energy under contract 89233218CNA000001. By approving this article, the publisher recognizes that the U.S. Government retains nonexclusive, royalty-free license to publish or reproduce the published form of this contribution, or to allow others to do so, for U.S. Government purposes. Los Alamos National Laboratory requests that the publisher identify this article as work performed under the auspices of the U.S. Department of Energy. Los Alamos National Laboratory strongly supports academic freedom and a researcher's right to publish; as an institution, however, the Laboratory does not endorse the viewpoint of a publication or guarantee its technical correctness. 


\section{Structured Membrane-electrode Interface for Highly Efficient PEM Fuel Cell}

\section{Gaoqiang Yang}

MPA-11, LANL

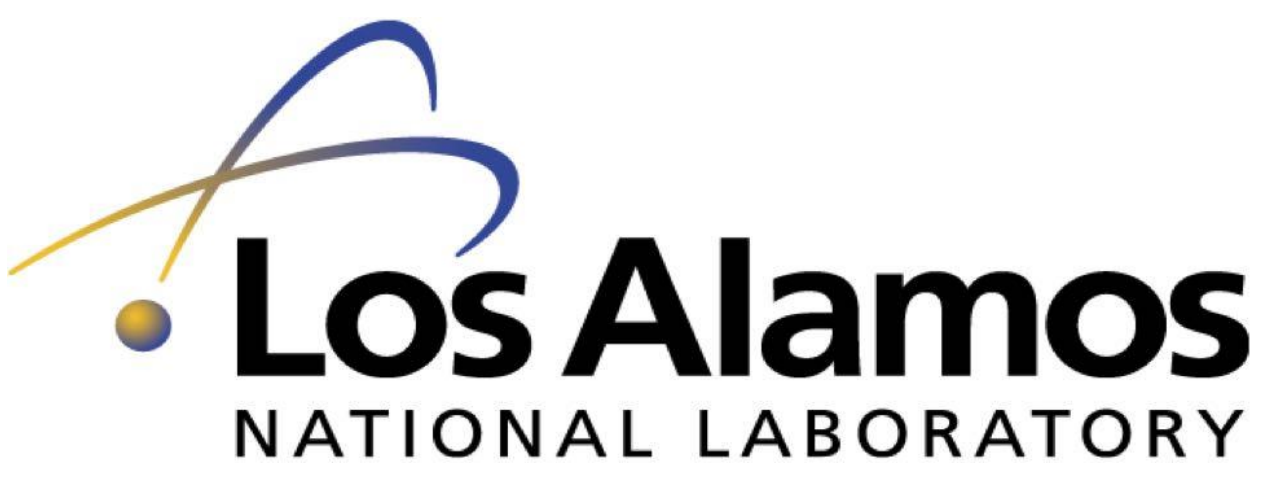




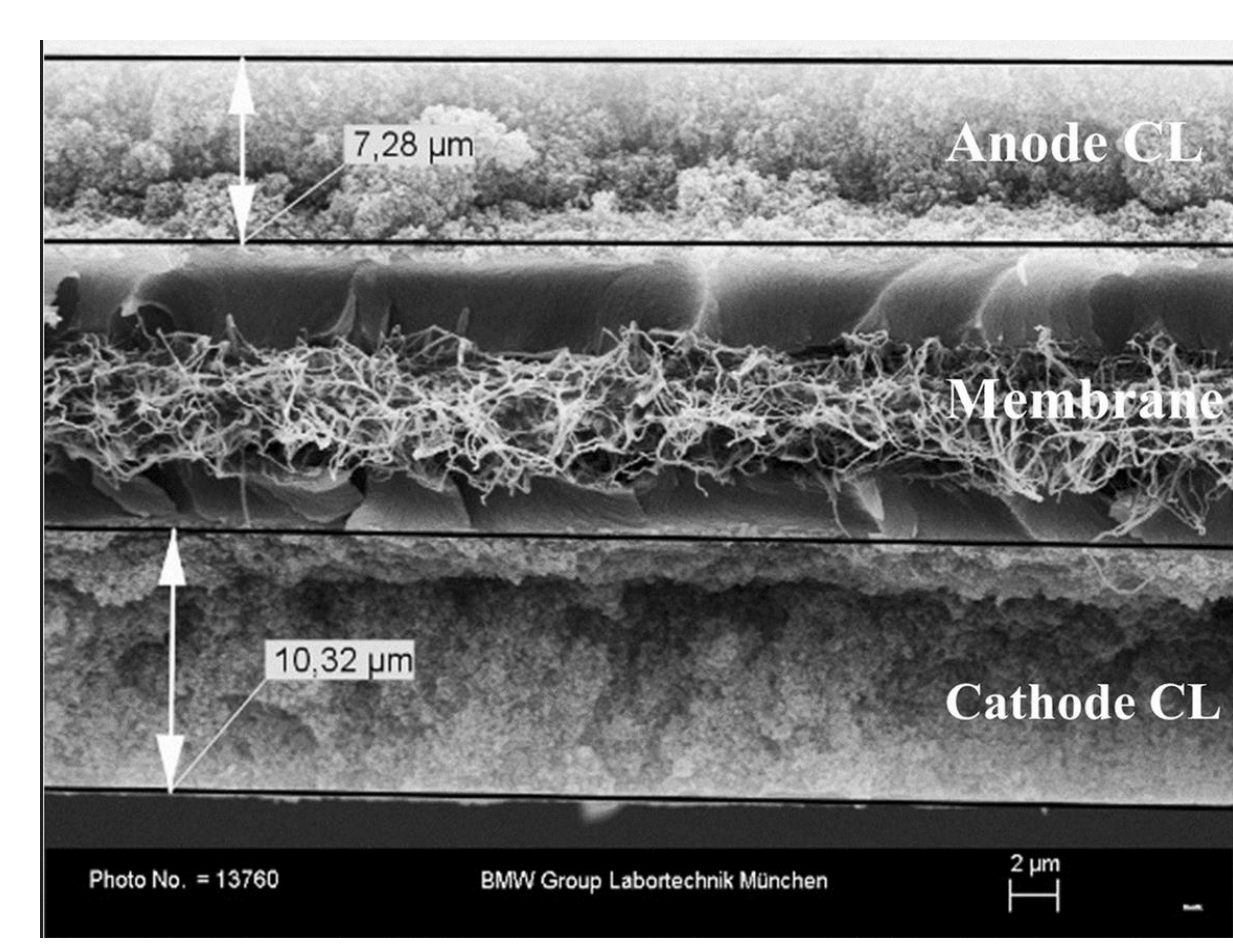

- Random mixture of:

- Pt on $\mathrm{C}$ support (catalyst)

- lon-conducting polymer (ionomer)

- Void space (pore)
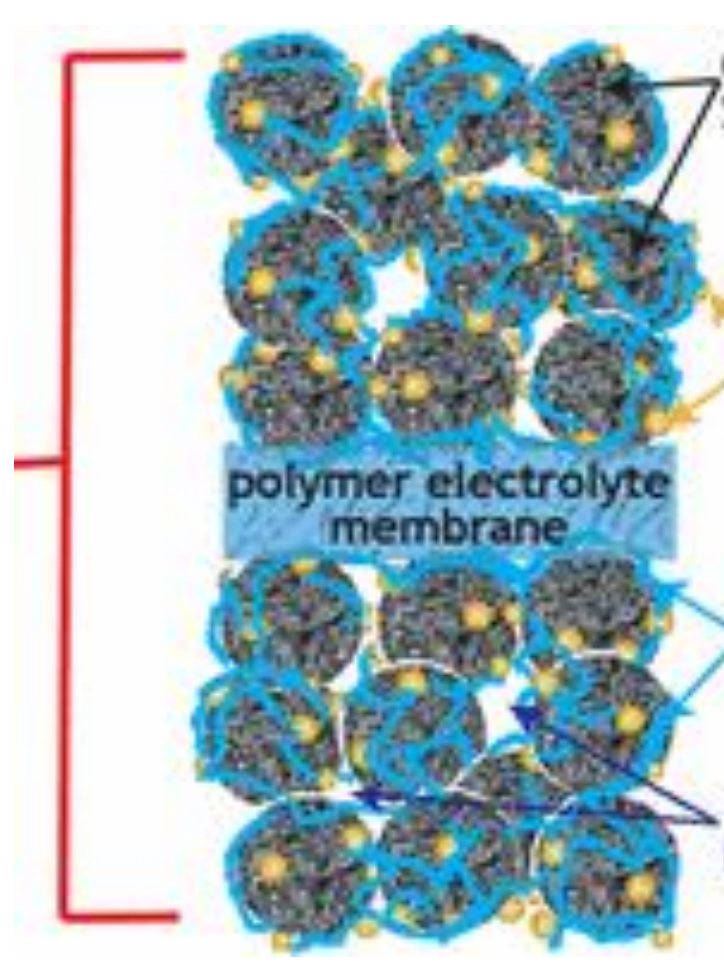

- Problem:

- Thick catalyst layer

- Long proton/electron transport pathway

- High mass transport resistance

- Low mass activity 


\section{Prior Work: NSTF}

(a)

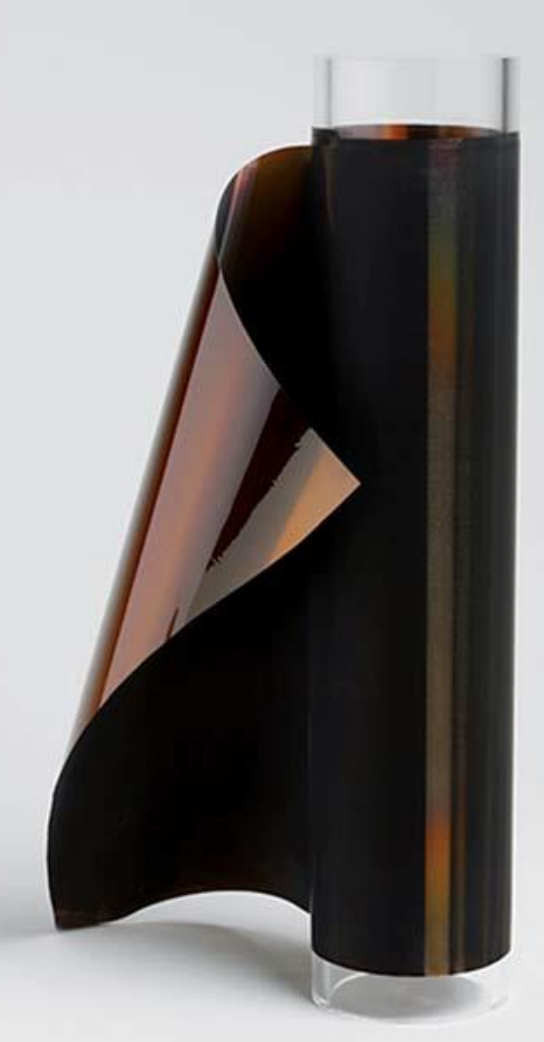

(b)

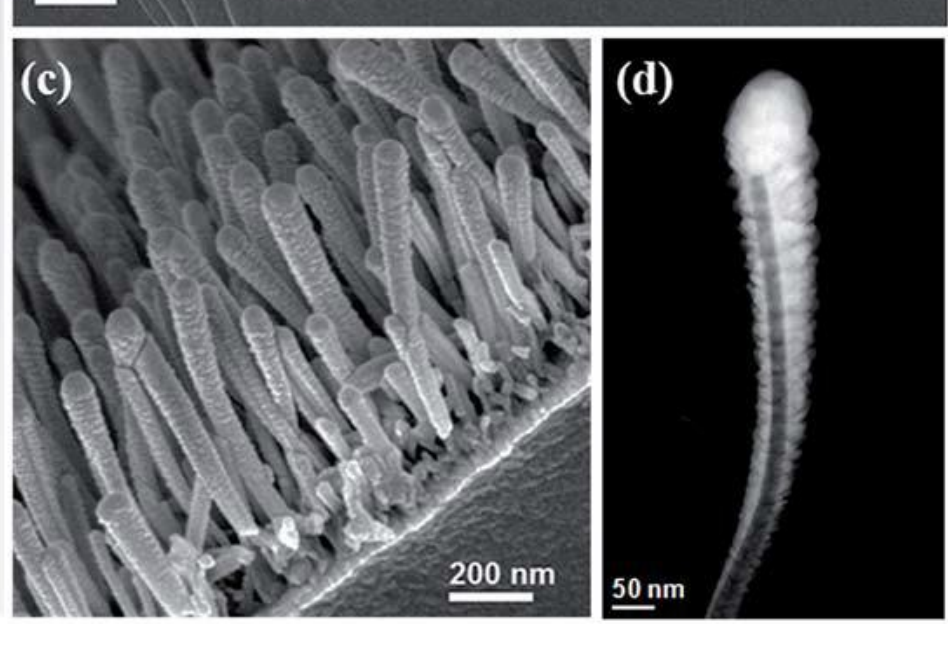

Cullen, David A., et al. Journal of Materials Chemistry A 3.21 (2015): 11660-11667.

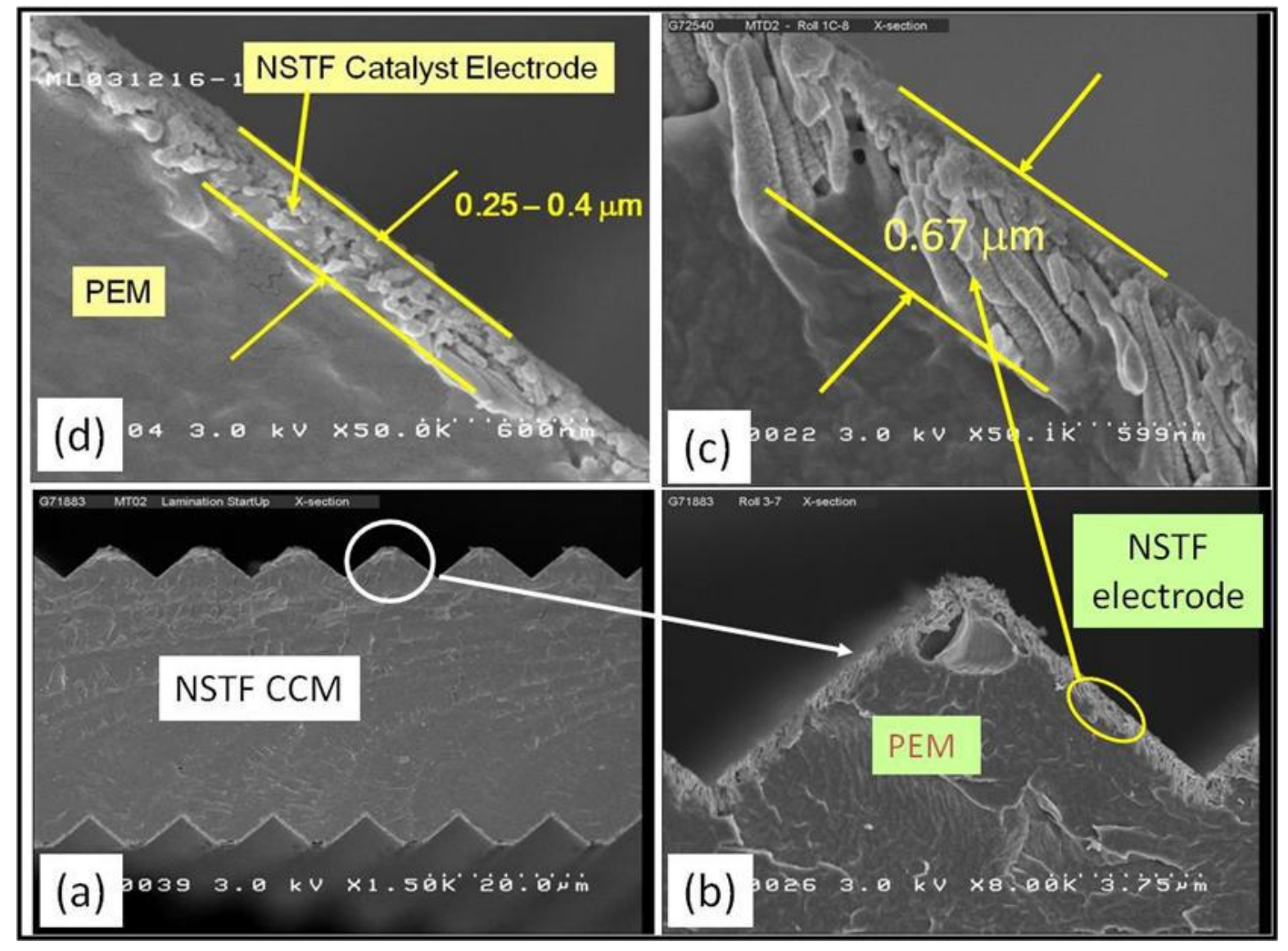

Debe, Mark K. Ecs Transactions 45.2 (2012): 47-68.

Whiskers are significantly compressed and deformed, lead to mass transport problem

Whiskers are compressed into the Nafion membrane, lead to reduction on active reaction sites.

Limited proton conductive paths in the nano pt-coated whiskers compared to ionomer-containing electrodes. 
-Arrayed membrane with Pillars 

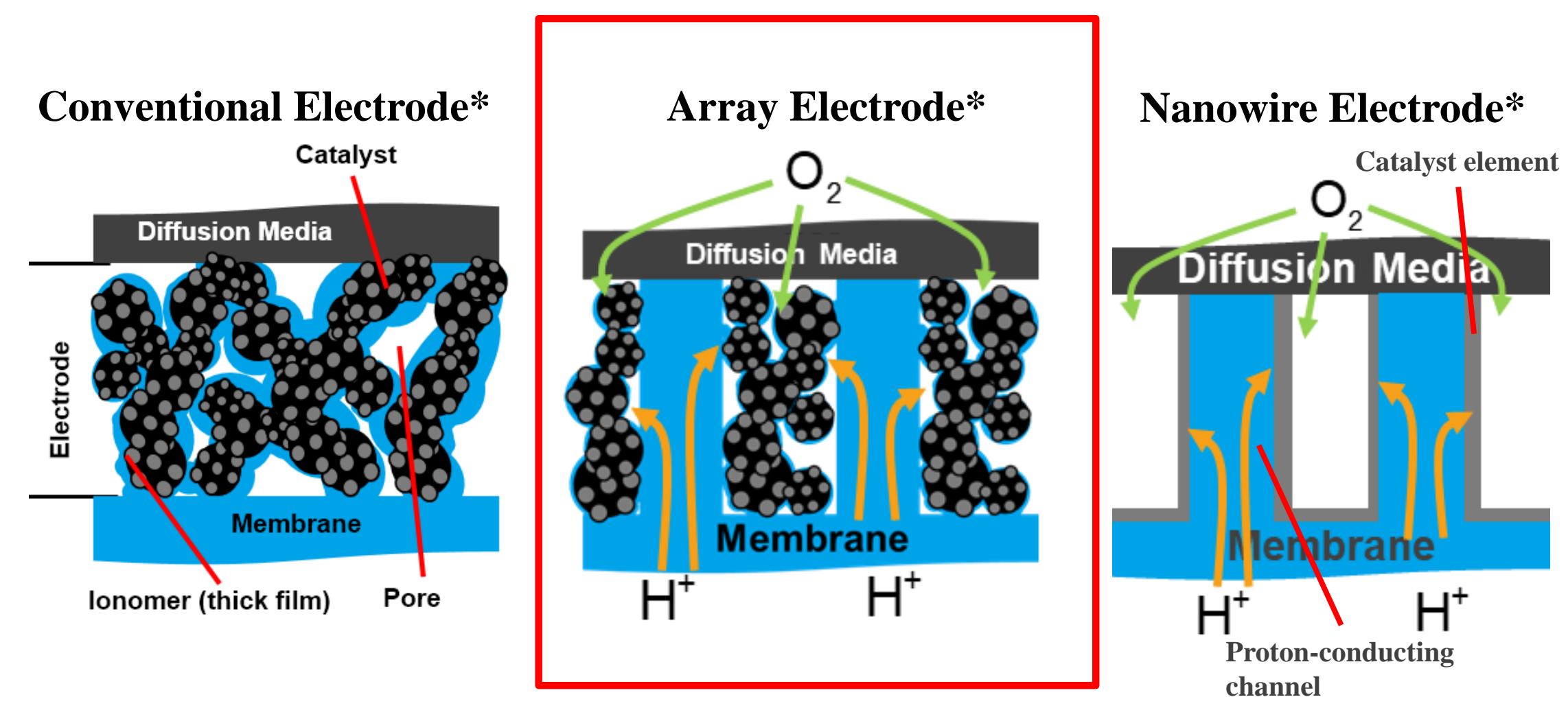

Meso-structured electrode relies on vertically-aligned ionomer channels for long-distance $\mathrm{H}+$ transport and catalyst support

$>$ Catalyzed elements can have reduced ionomer content

*not to scale 


\section{Fabrication Process of Ordered Array Electrode}

\section{Template}

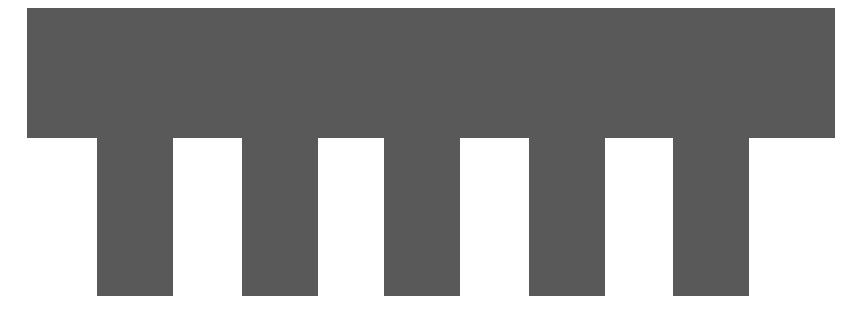

Hot-pressing of template onto polymer electrolyte membrane (Nafion $^{\mathrm{TM}}$ )

Templated Nafion ${ }^{\mathrm{TM}}$ Pillar Array

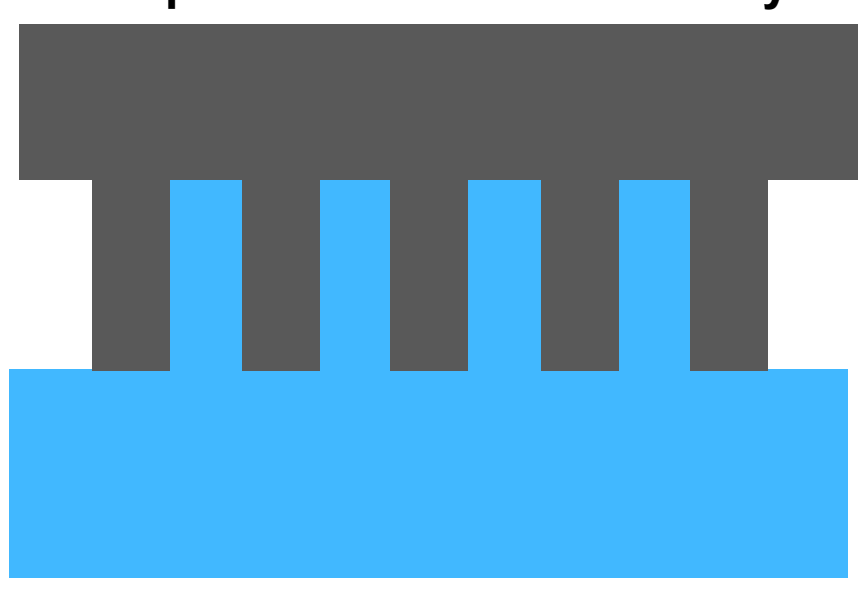

\section{Ordered Array Electrode}

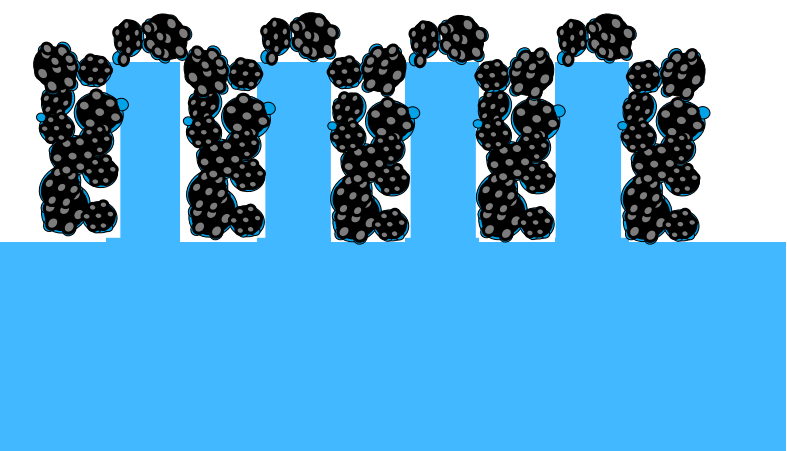

Catalyst Deposition (Ultrasonic Ink Spraying)

Template Removal (Alkaline Etch) 


\section{Fabrication Process of the Ordered Array Electrode}

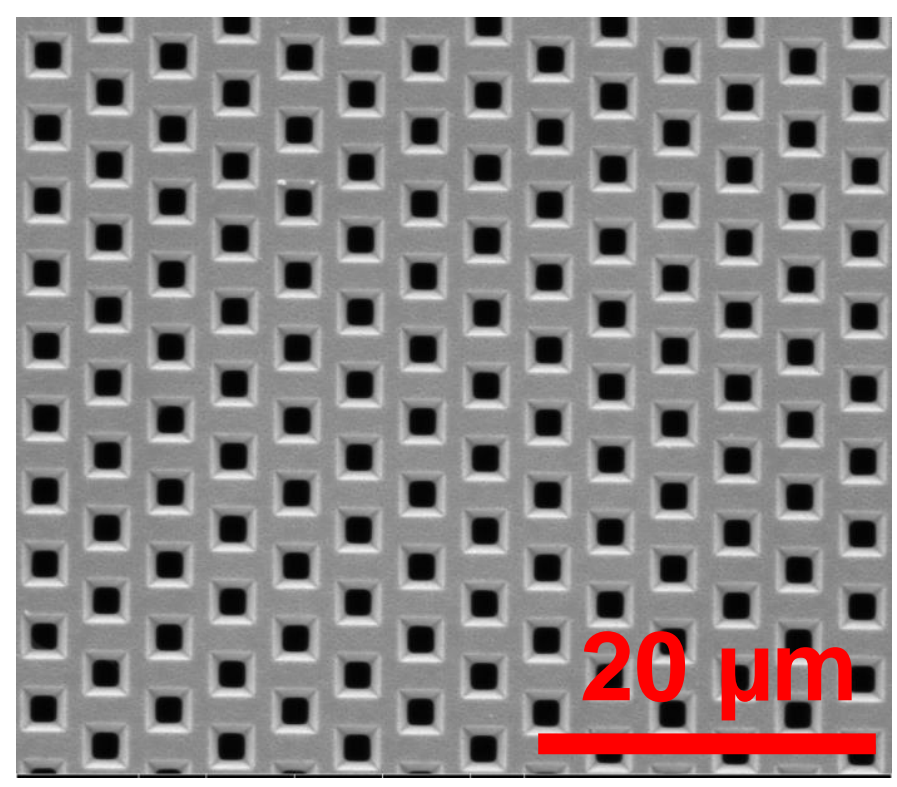

Si template

Pillar collapse during catalyst deposition.
Hot-press with PEM

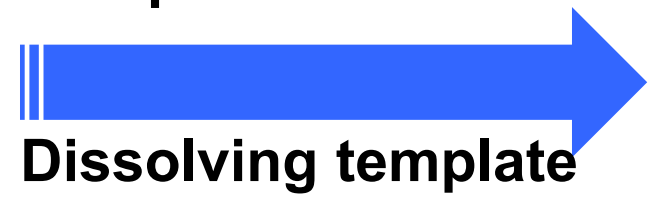

Nafion Arrayed pillars
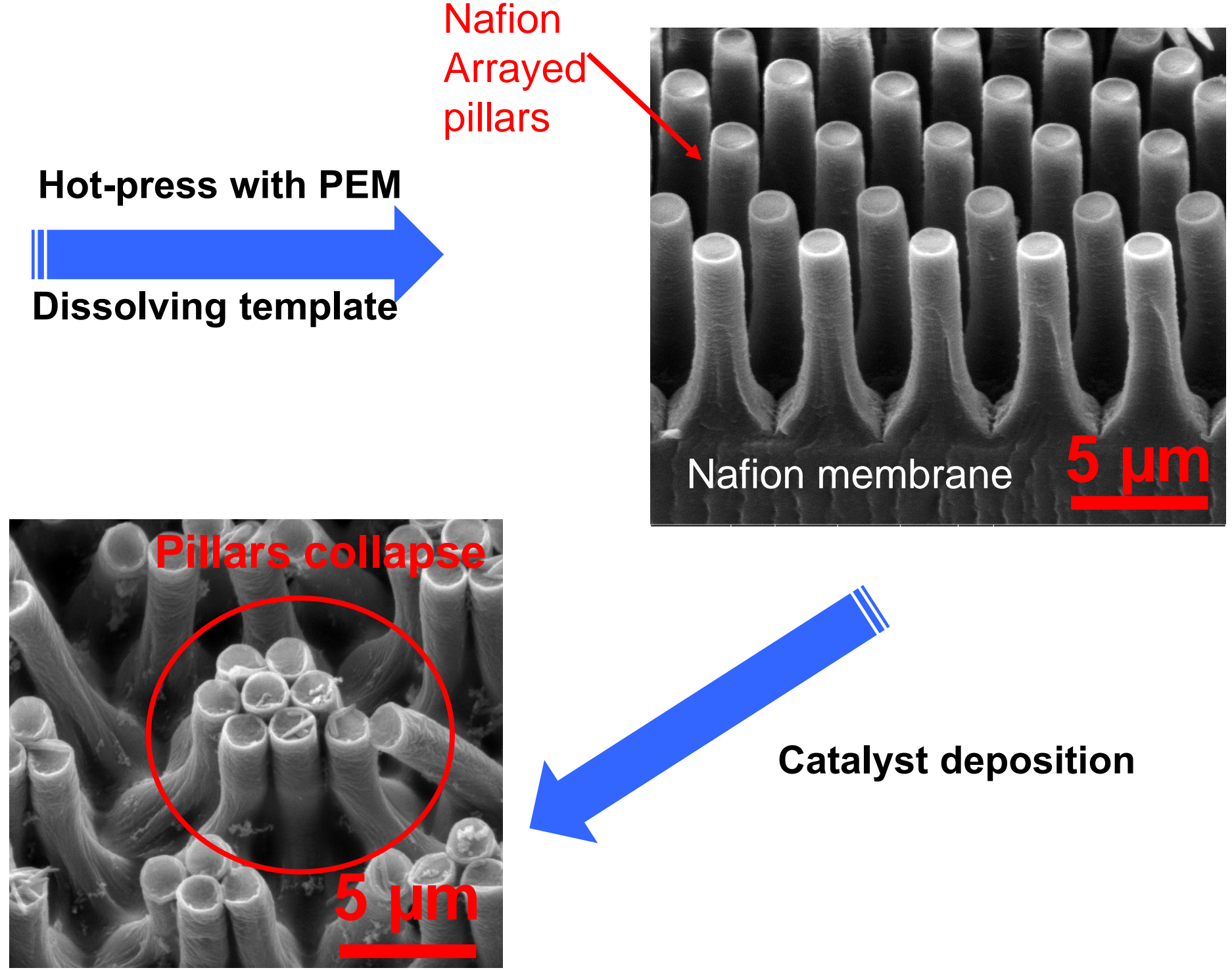


\section{Preventing Nafion pillar collapse}

\section{- Methods:}

- Different forms $\left(\mathrm{H}^{+}, \mathrm{Na}^{+}, \mathrm{K}^{+}\right)$

- Templates with different features

- Different coating methods

- Different deposition parameters

- Pillar length: $10 \mu \mathrm{m}$

- Spray coating:

- Ink flow rate: $0.02 \mathrm{ml} / \mathrm{min}$ (ultralow)

- Gas flow rate: $0.4 \mathrm{ml} / \mathrm{min}$

- High nozzle-sample distance: $60 \mathrm{~cm}$

Accomplishment \#1: Development of a robust method for catalyst deposition with prevention of pillar collapse.
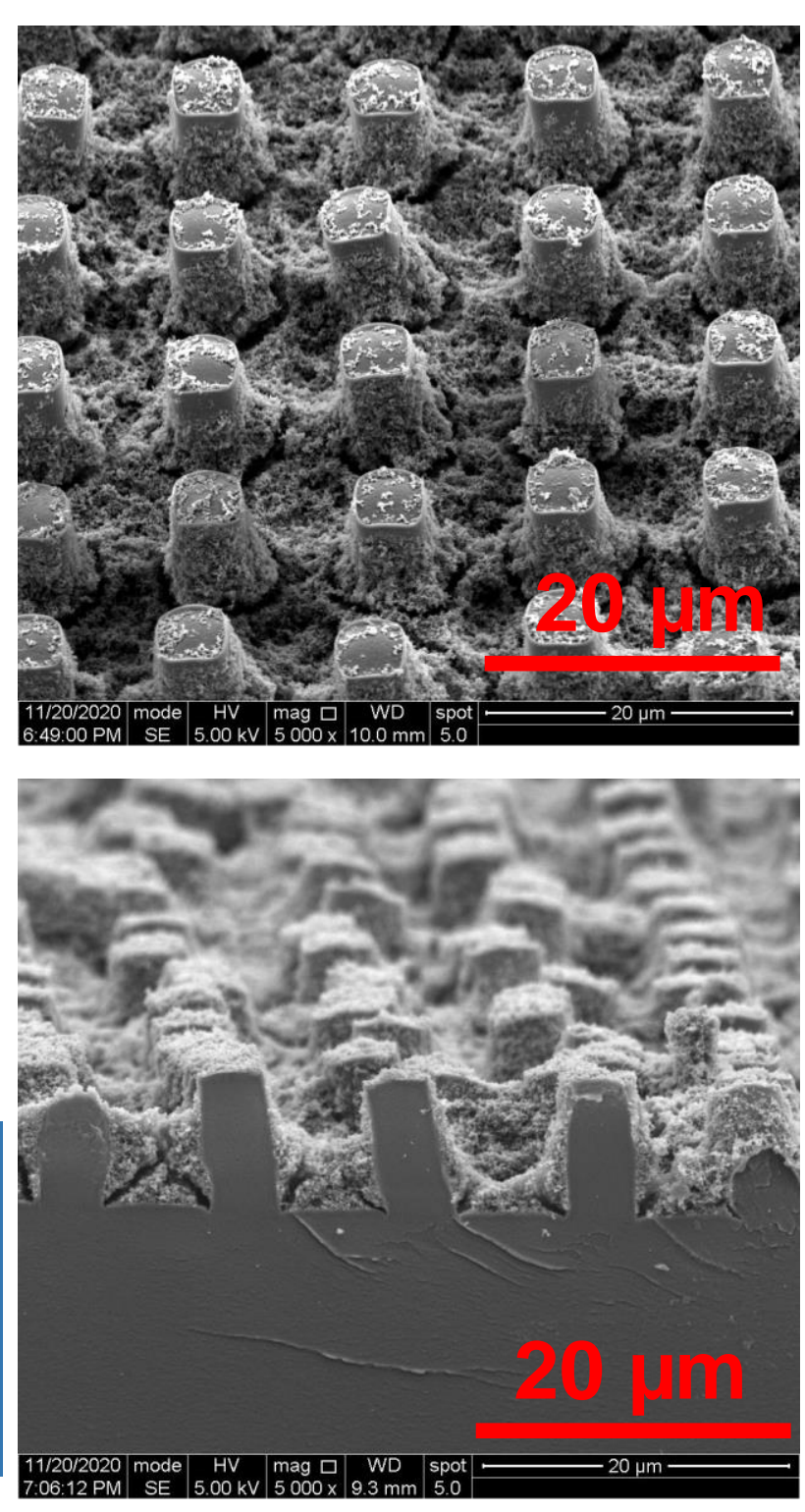
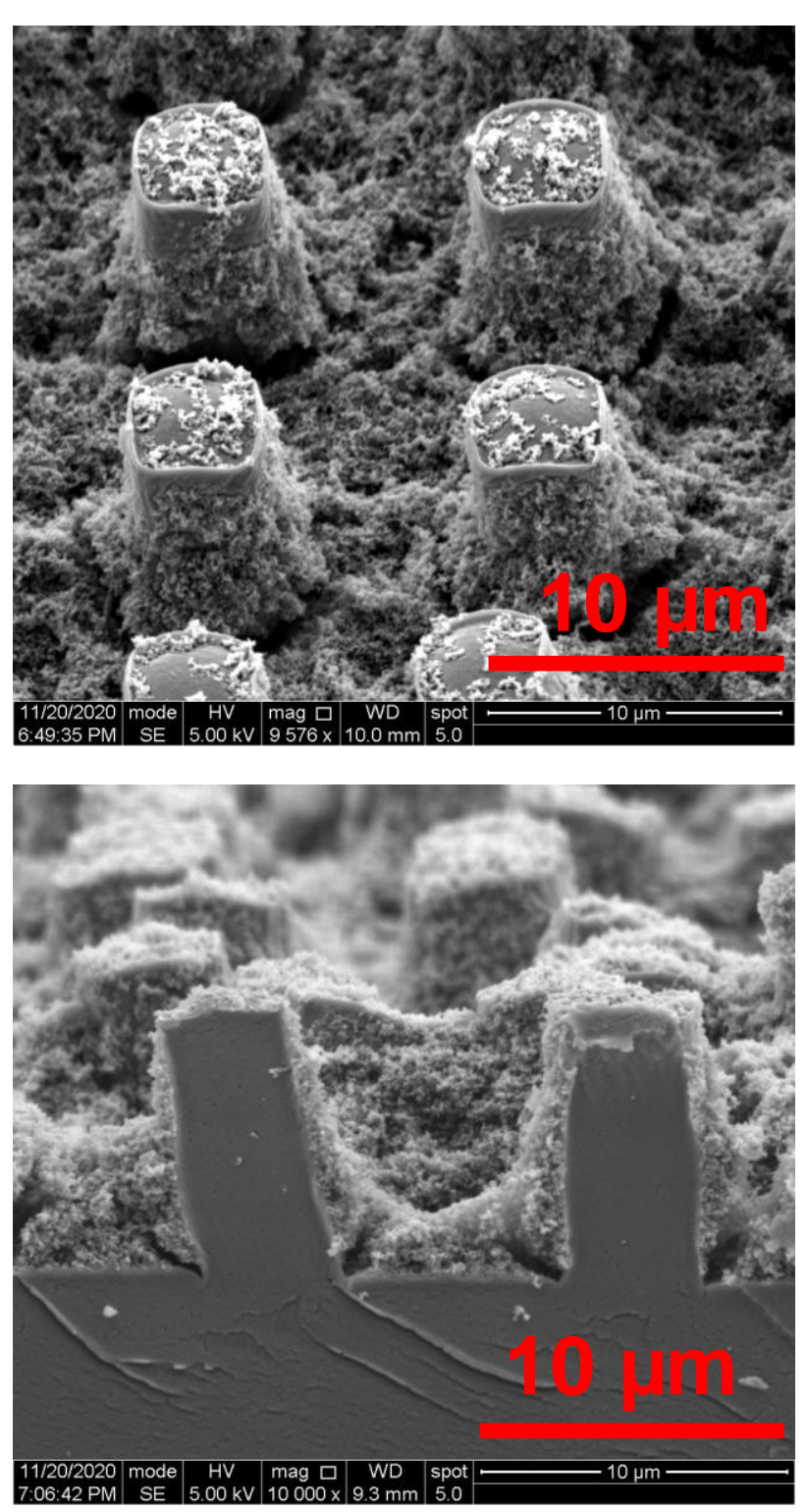
Regular pillar: 15 um for 0.3 mg/cm² loading

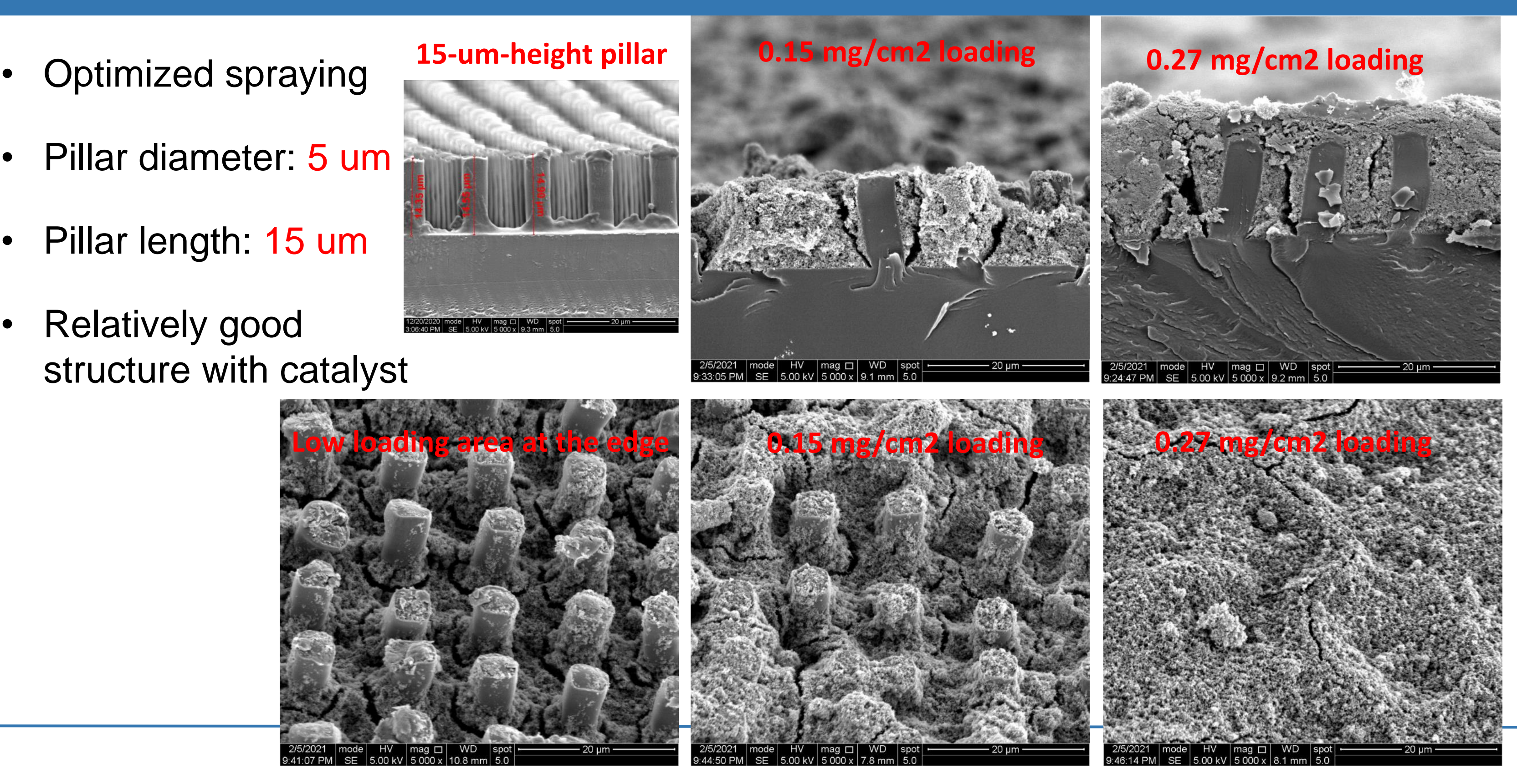


- Arrayed membrane provide a better performance compared to flat membrane

- Patterned membrane provide a smaller HFR, due to the reduced Nafion content in catalyst ink and increased proton transport paths in Nafion pillars.
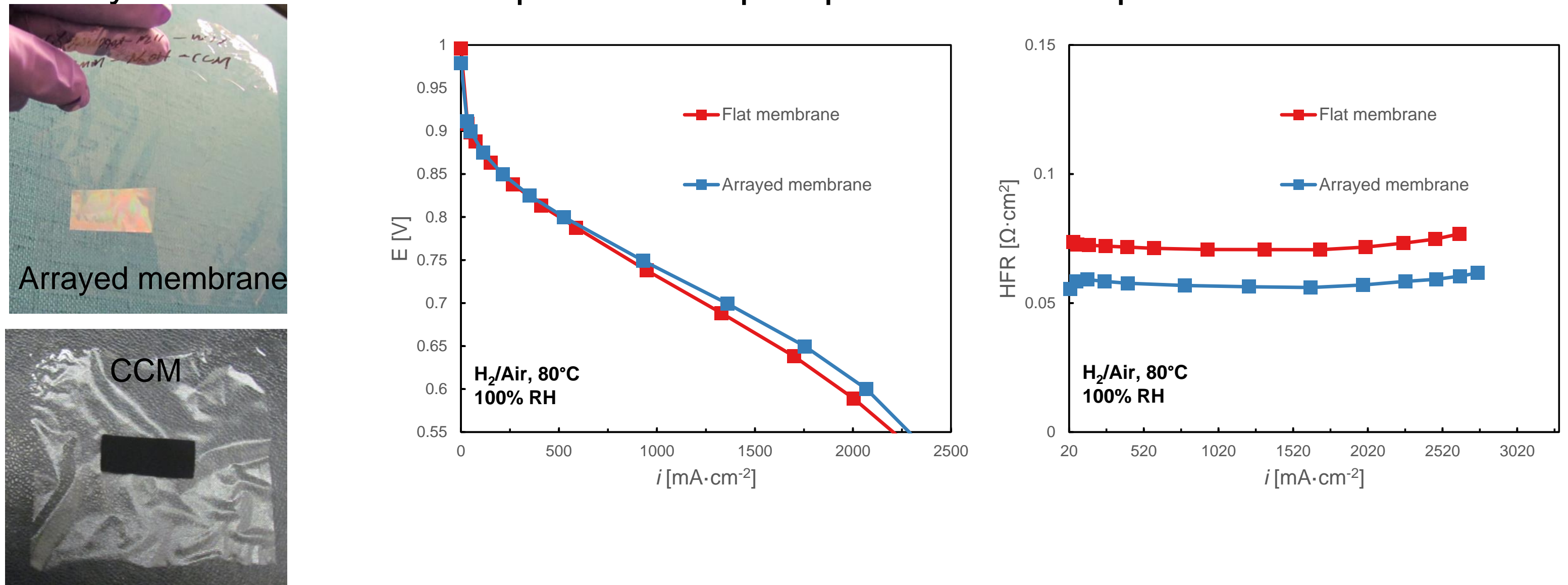
Conventional Electrode*

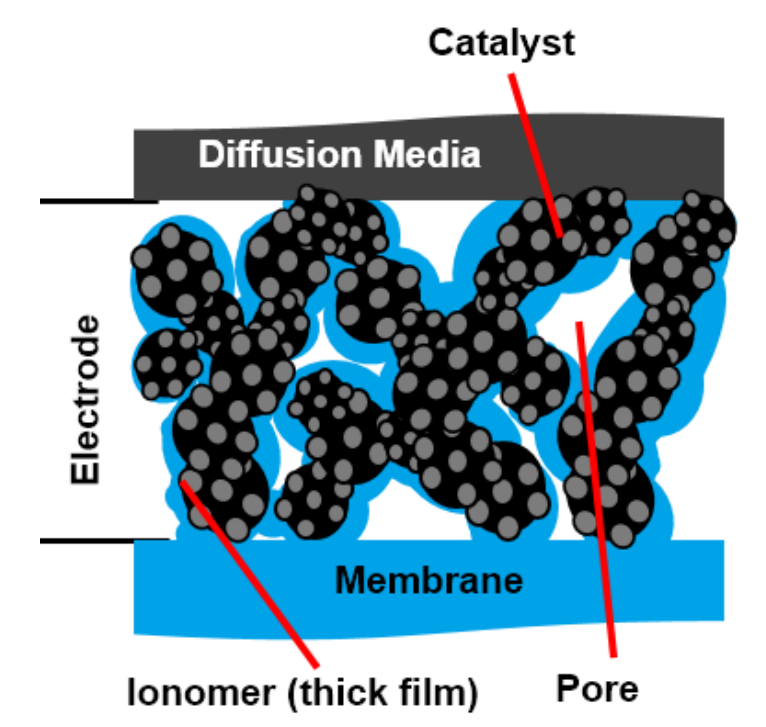

Array Electrode*

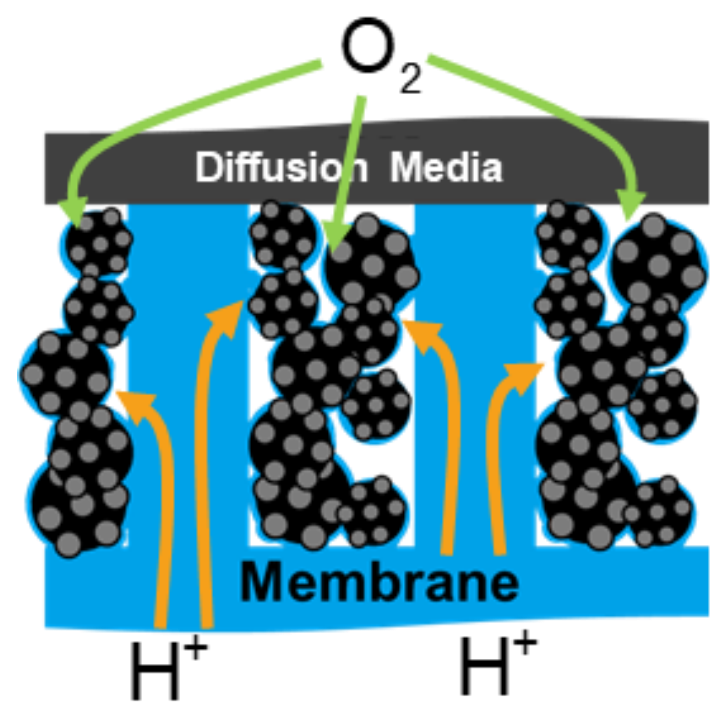

\section{Co-axial Nanowire Electrode*}

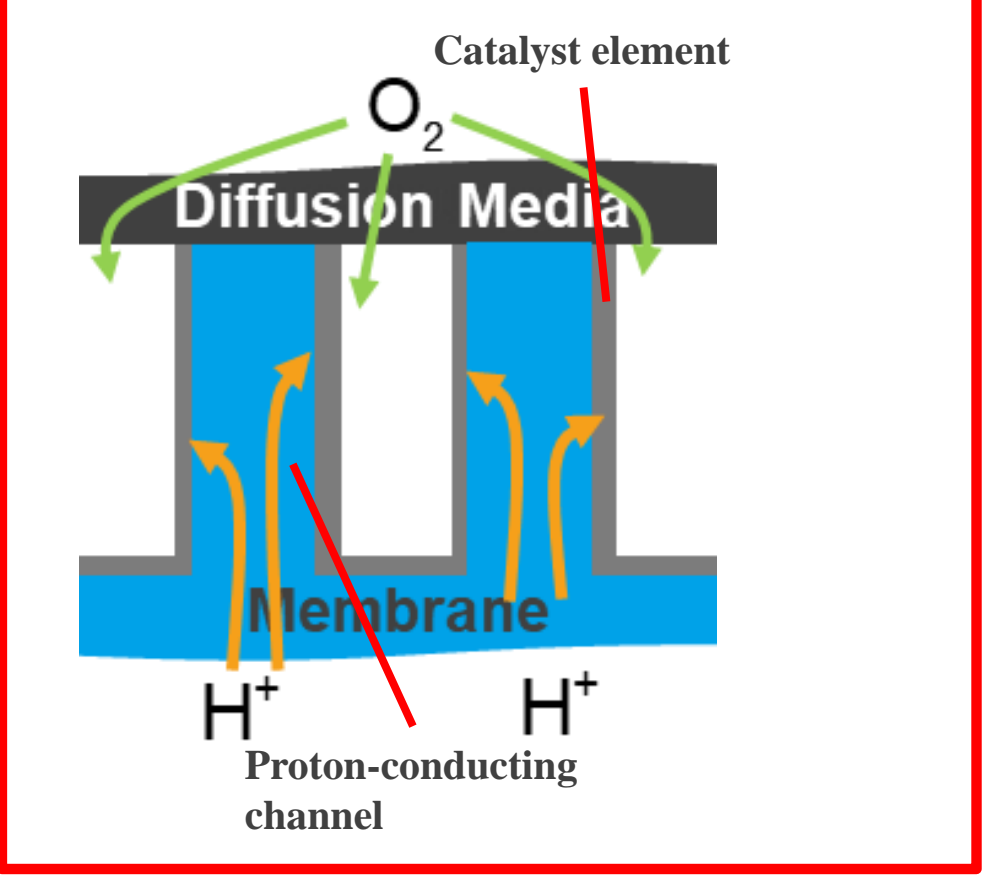

- CANE relies on vertically-aligned ionomer channels for long-distance $\mathrm{H}^{+}$ transport and catalyst support

- Electrode with thin Pt film has reduced ionomer/carbon content 


\section{Fabrication Of Co-Axial Nanowire Electrodes}
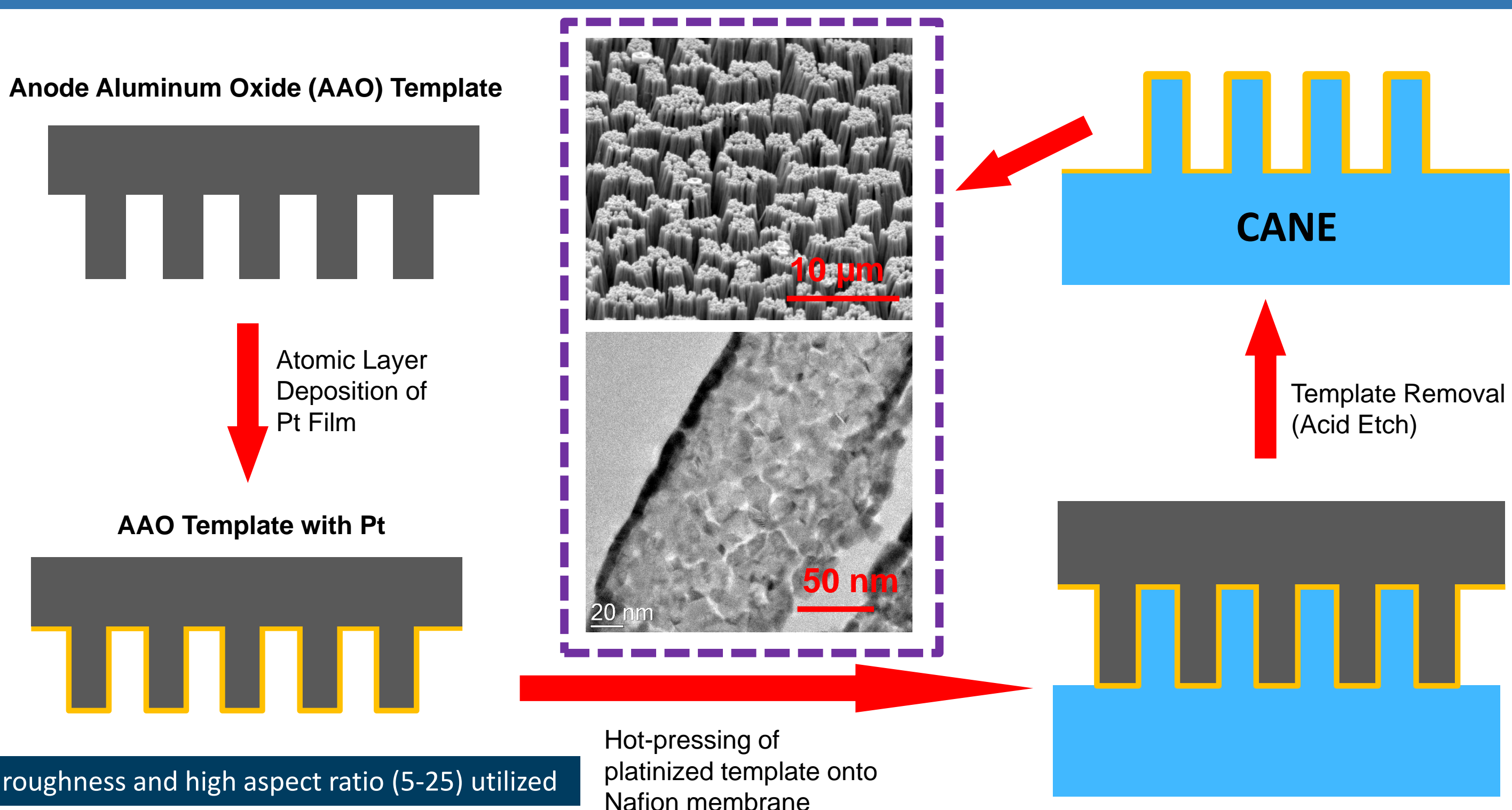
Co-Axial Nanowire Electrodes

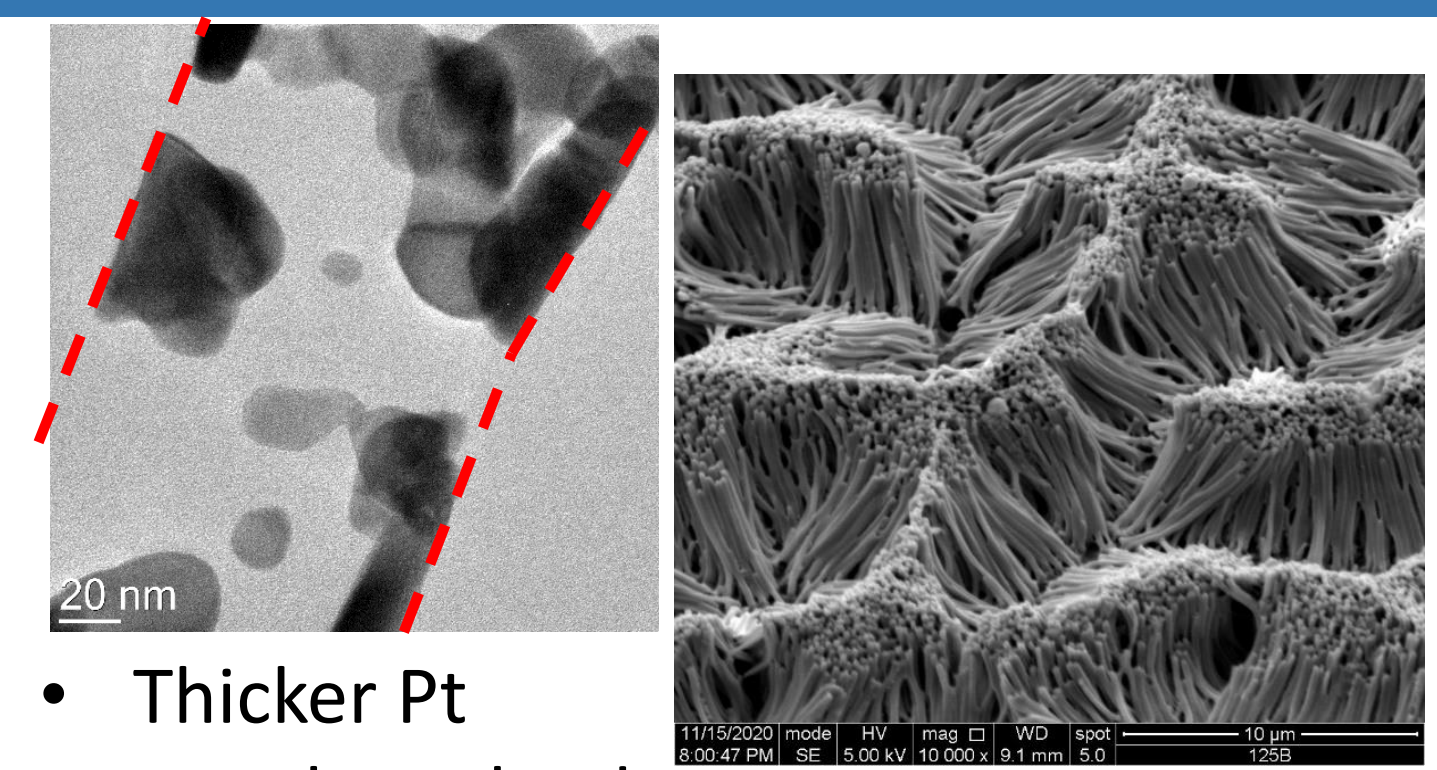
nanolayer leads to vertical pillars
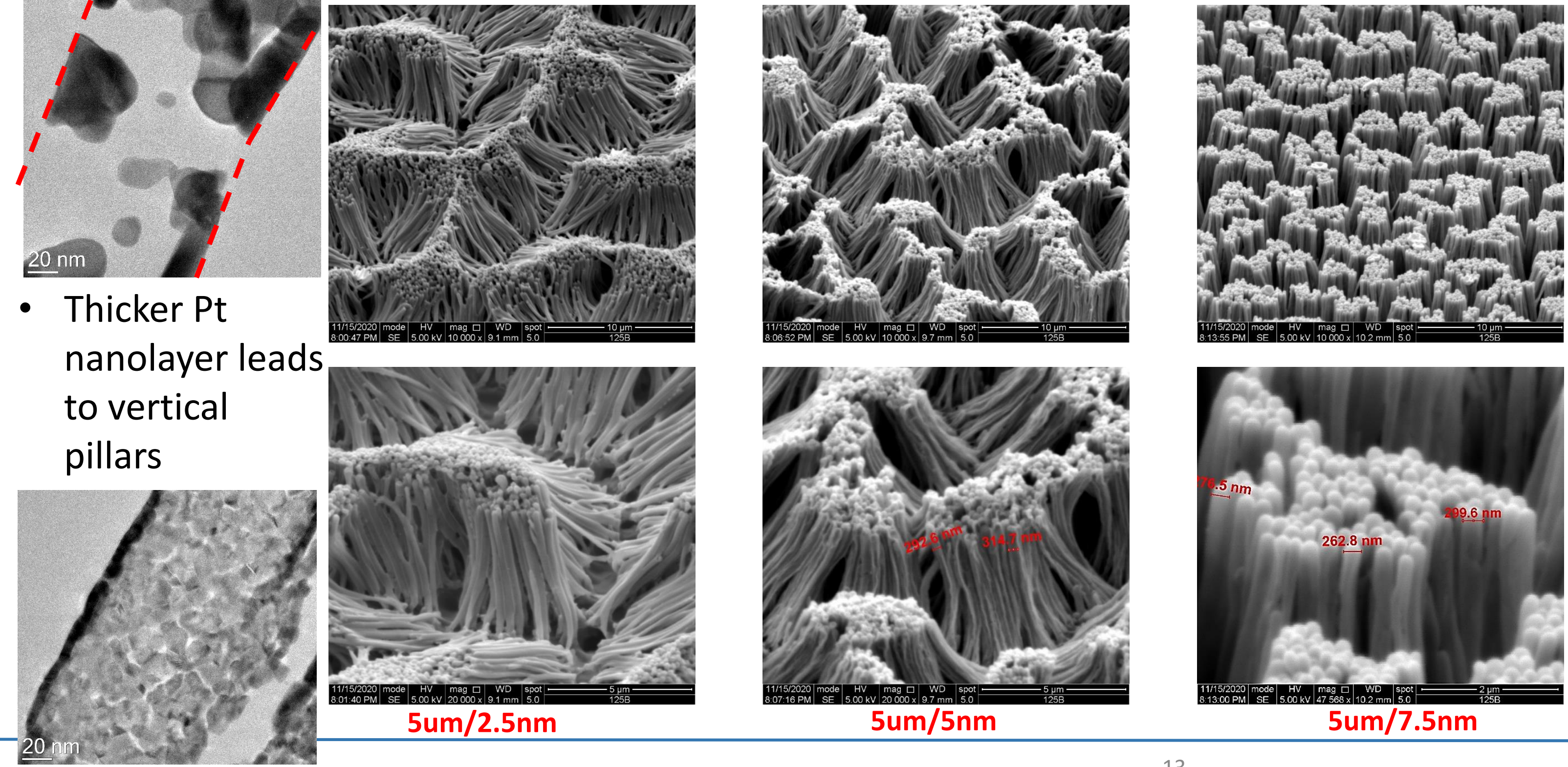

$5 \mathrm{um} / 2.5 \mathrm{~nm}$

$5 \mathrm{um} / 5 \mathrm{~nm}$

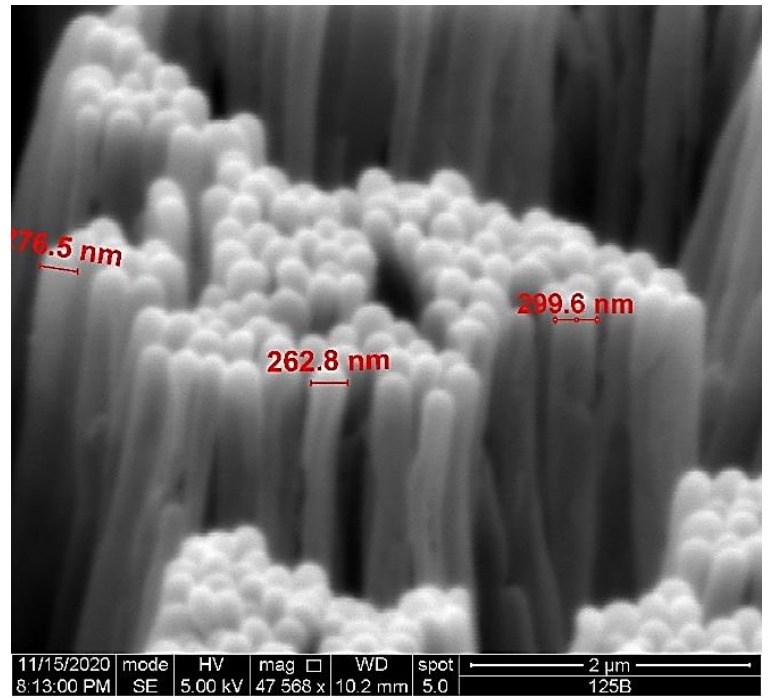

$5 \mathrm{um} / 7.5 \mathrm{~nm}$ 


\section{Co-Axial Nanowire Electrodes}
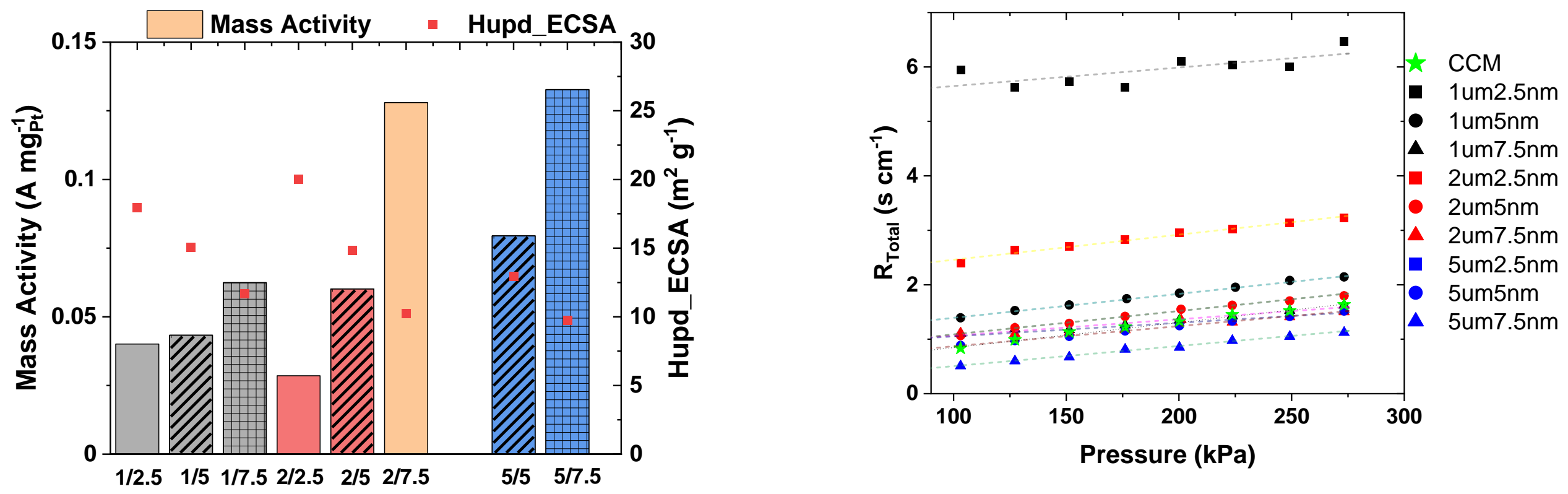

- Higher mass activity and smaller RO2 explain better performance of $5 \mu \mathrm{m} 7.5 \mathrm{~nm}$

- Conventional CCM: 0.18A/mg $\mathrm{mpt}_{\mathrm{Pt}}$ and $65 \mathrm{~m} 2 / \mathrm{g}_{\mathrm{pt}}$

- $5 \mu \mathrm{m7} .5 \mathrm{~nm}$ has a lowest RO2

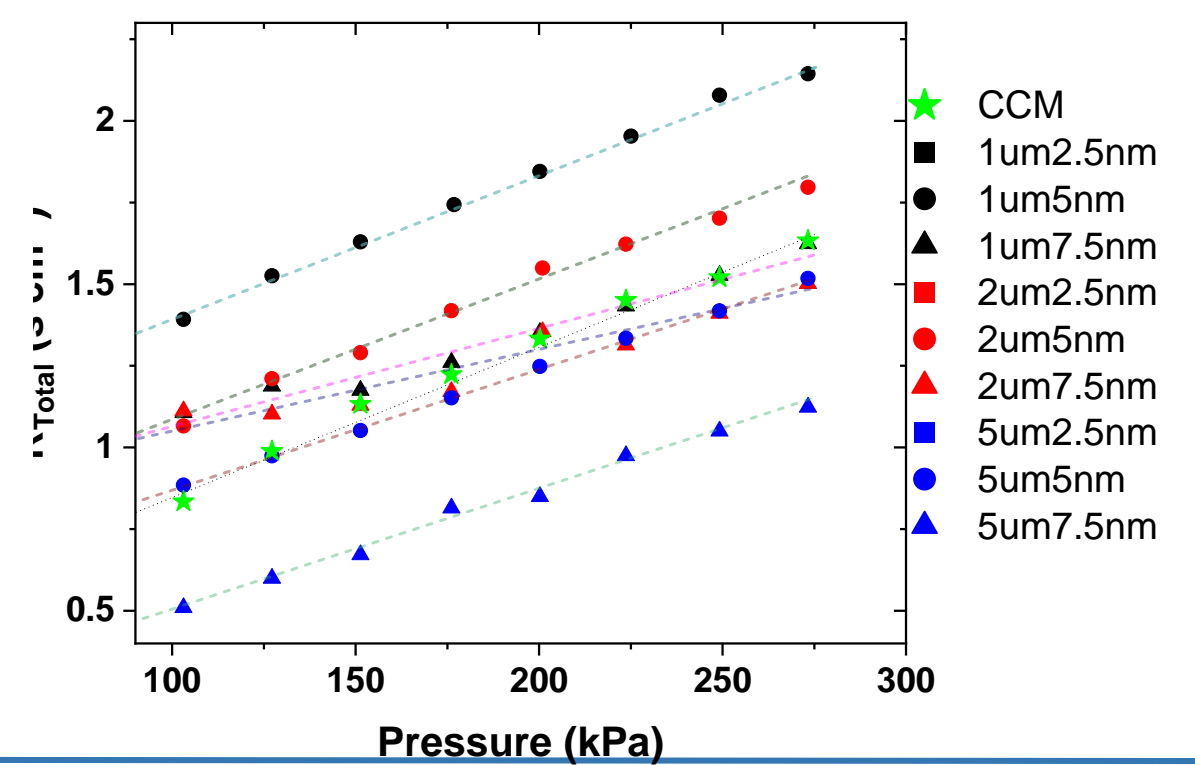




\section{Co-Axial Nanowire Electrodes}
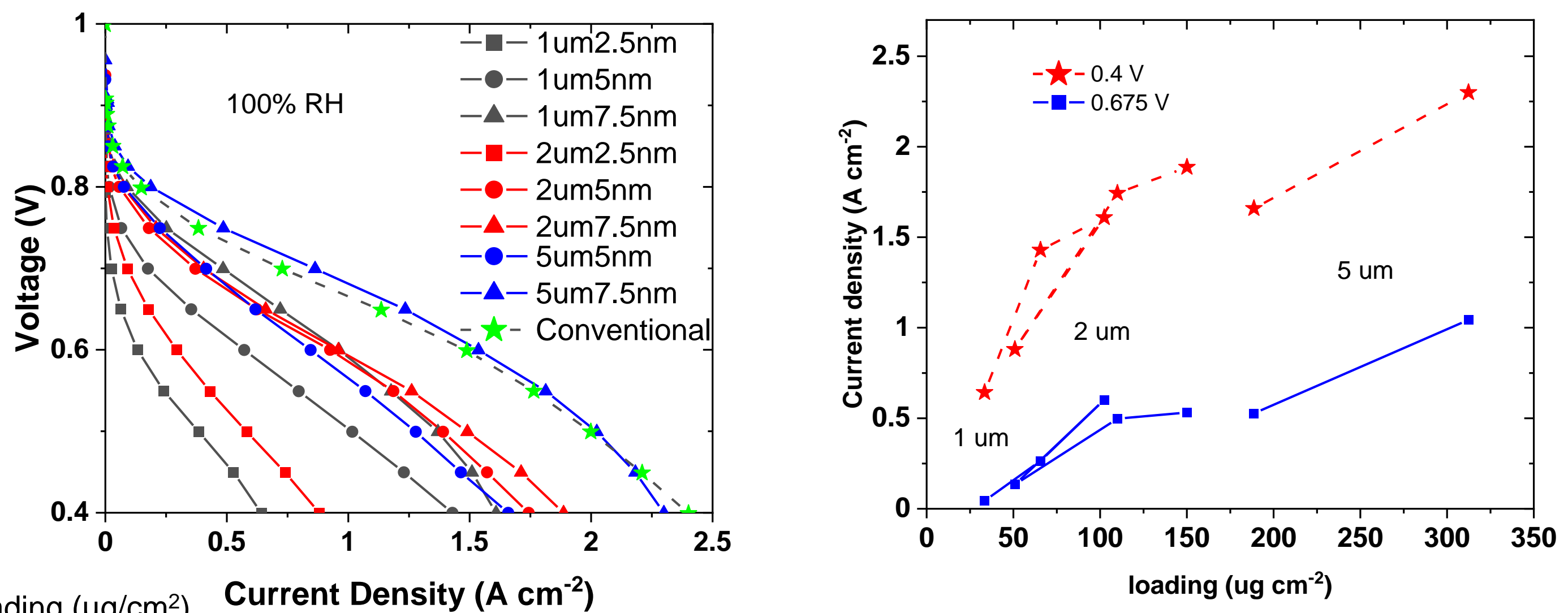

Pt loading $\left(\mu \mathrm{g} / \mathrm{cm}^{2}\right)$ Current Density $\left(\mathbf{A ~ c m}^{-2}\right)$

\begin{tabular}{|c|c|c|c|}
\hline $\begin{array}{l}\text { Height } \\
\text { ickness }\end{array}$ & $1 \mu \mathrm{m}$ & $2 \mu \mathrm{m}$ & $5 \mu \mathrm{m}$ \\
\hline & 33.4 & $50 c$ & 51.3 \\
\hline & 65.7 & 110 & 188.7 \\
\hline & 100 & 150.1 & 312. \\
\hline
\end{tabular}

- Good performance was achieved by CANEs $(5 \mu \mathrm{m} 7.5 \mathrm{~nm})$

- However, loading is not the only reason for good performance

- Similar performance observed from CANEs with different loadings 


\section{-Backup}




\section{Co-Axial Nanowire Electrodes: Different RHs}

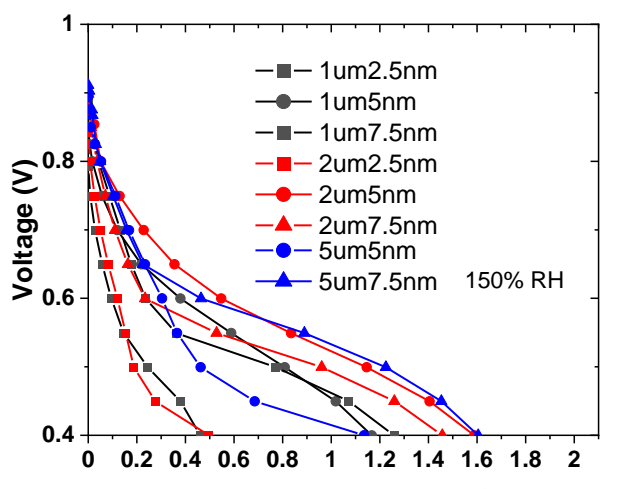

Current Density $\left(\mathrm{A} \mathrm{cm}^{-2}\right)$
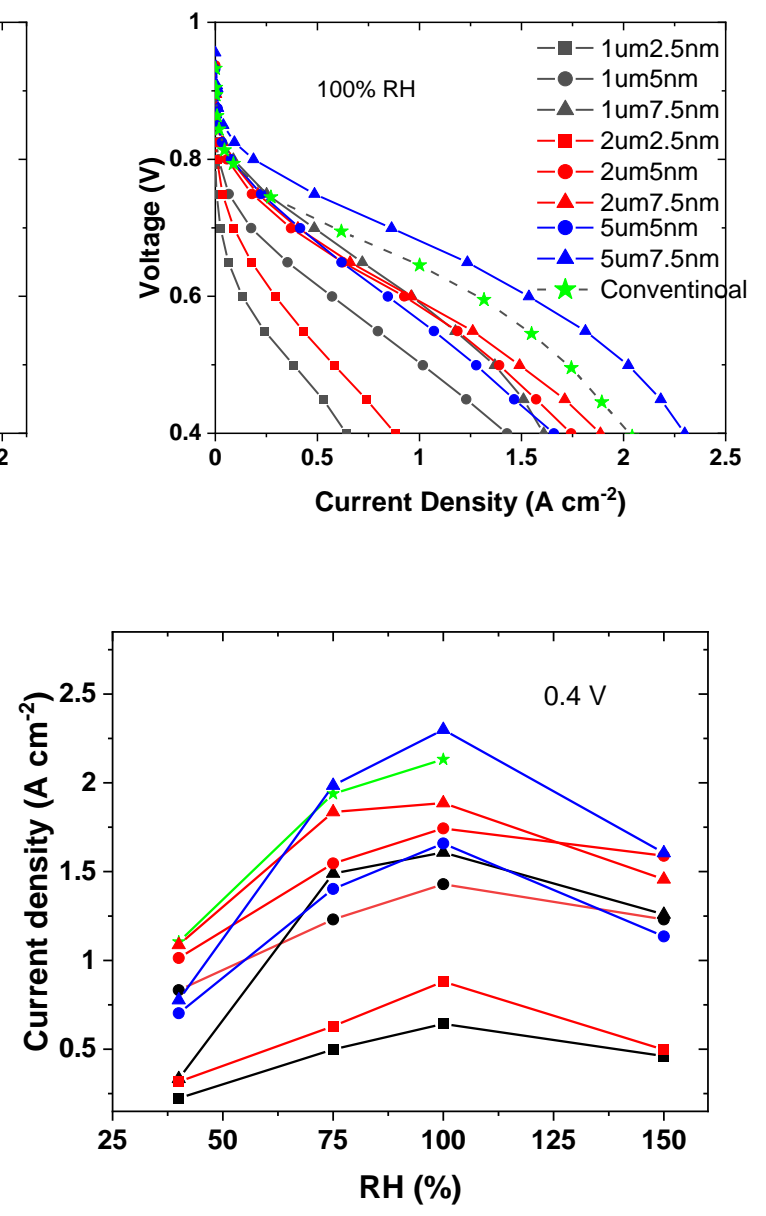
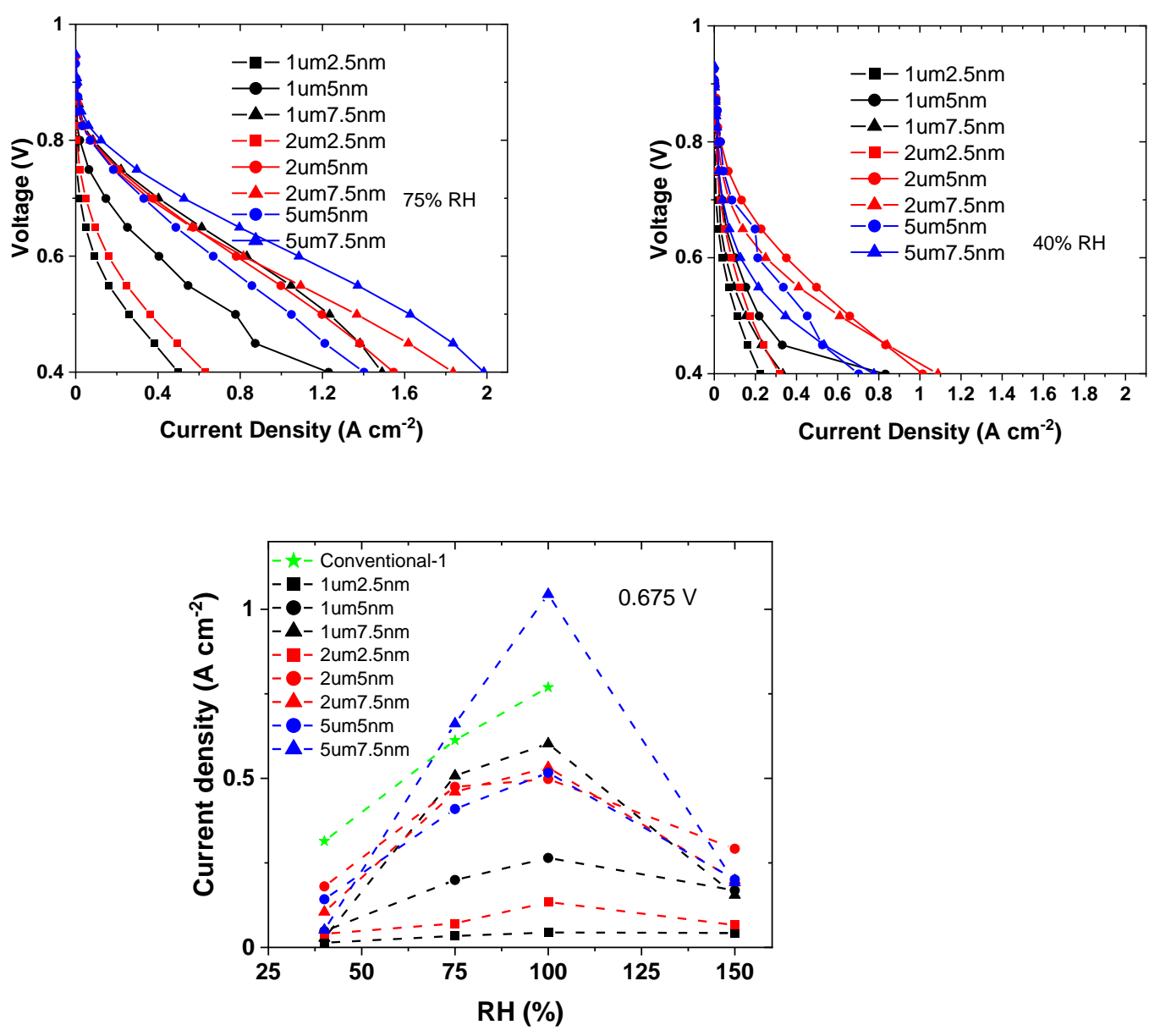

- $5 \mu \mathrm{m} 7.5 \mathrm{~nm}$ provide best performance at $100 \% \mathrm{RH}$

- Performance of $5 \mu \mathrm{m} 7.5 \mathrm{~nm}$ is reduced at high and low RH (150\% and $40 \%$ )

- CANE electrodes are sensitive to RH 


\section{Co-Axial Nanowire Electrodes: Different RHs}
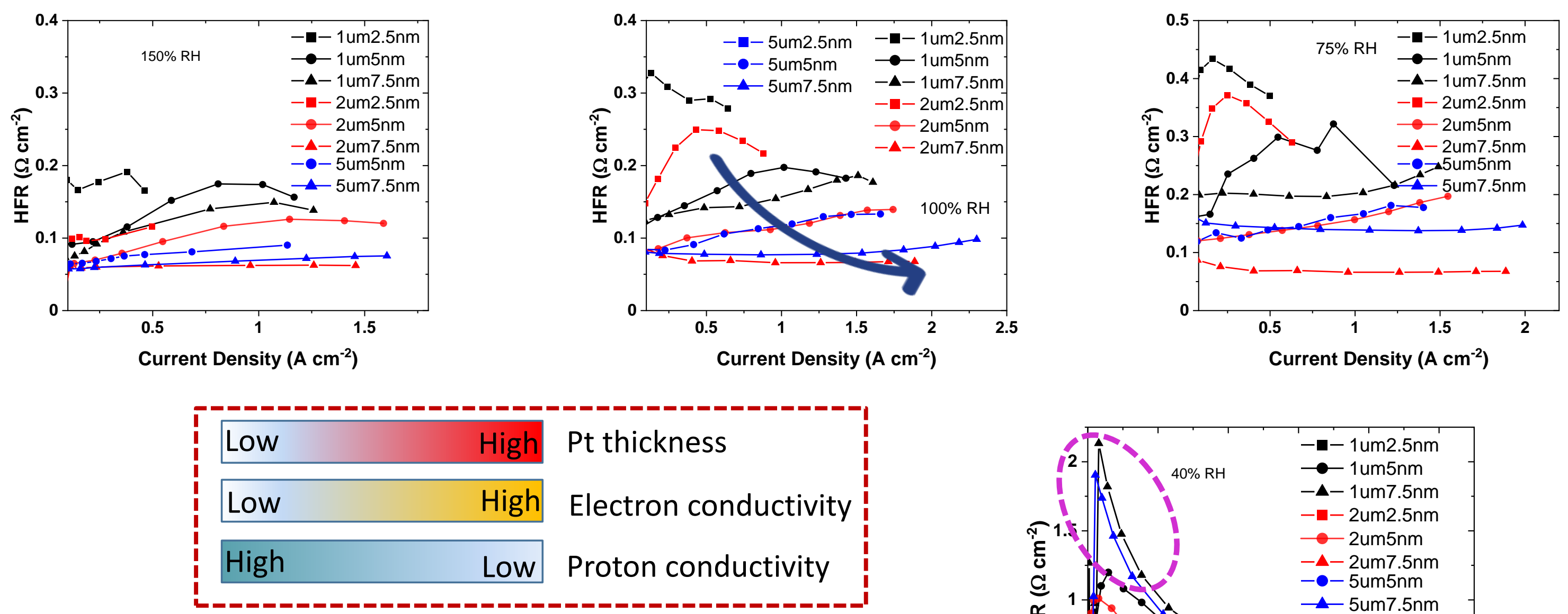

- Thicker Pt layer leads to higher HFR at $40 \%$ $\mathrm{RH}$, due to the smaller water permeability and higher protonic resistance.

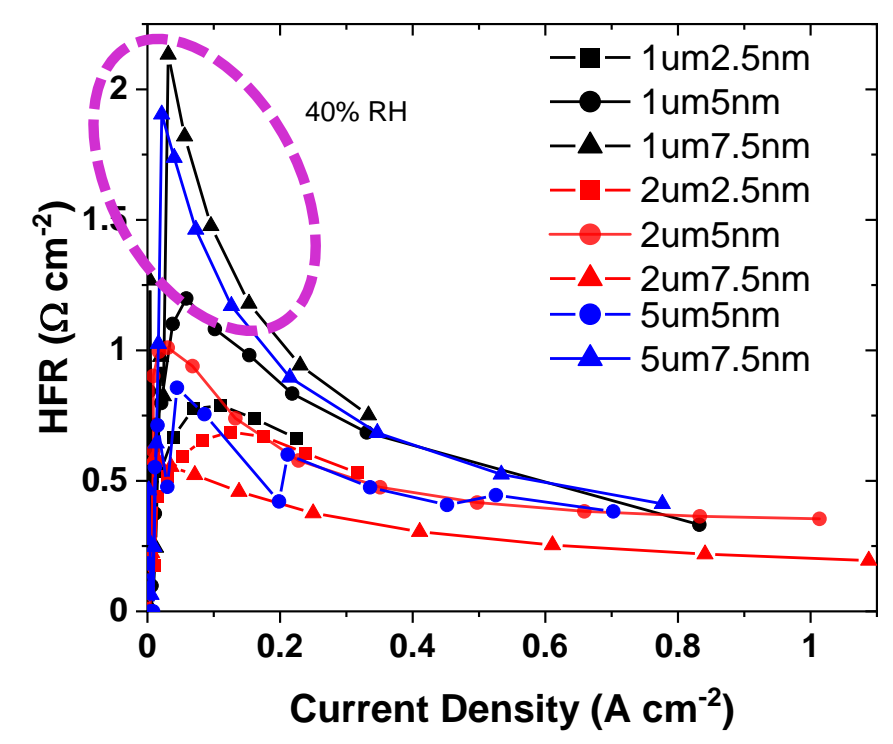




\section{CANE: C-filler}

- Sonication procedures: $2 \mathrm{~min}$ probe $+3 \mathrm{~h}$ bath

- XC-72 ink with $0.1 \mathrm{I} / \mathrm{C}$

- Carbon concertation: $0.05 \%$

- Catalysts cover pillars
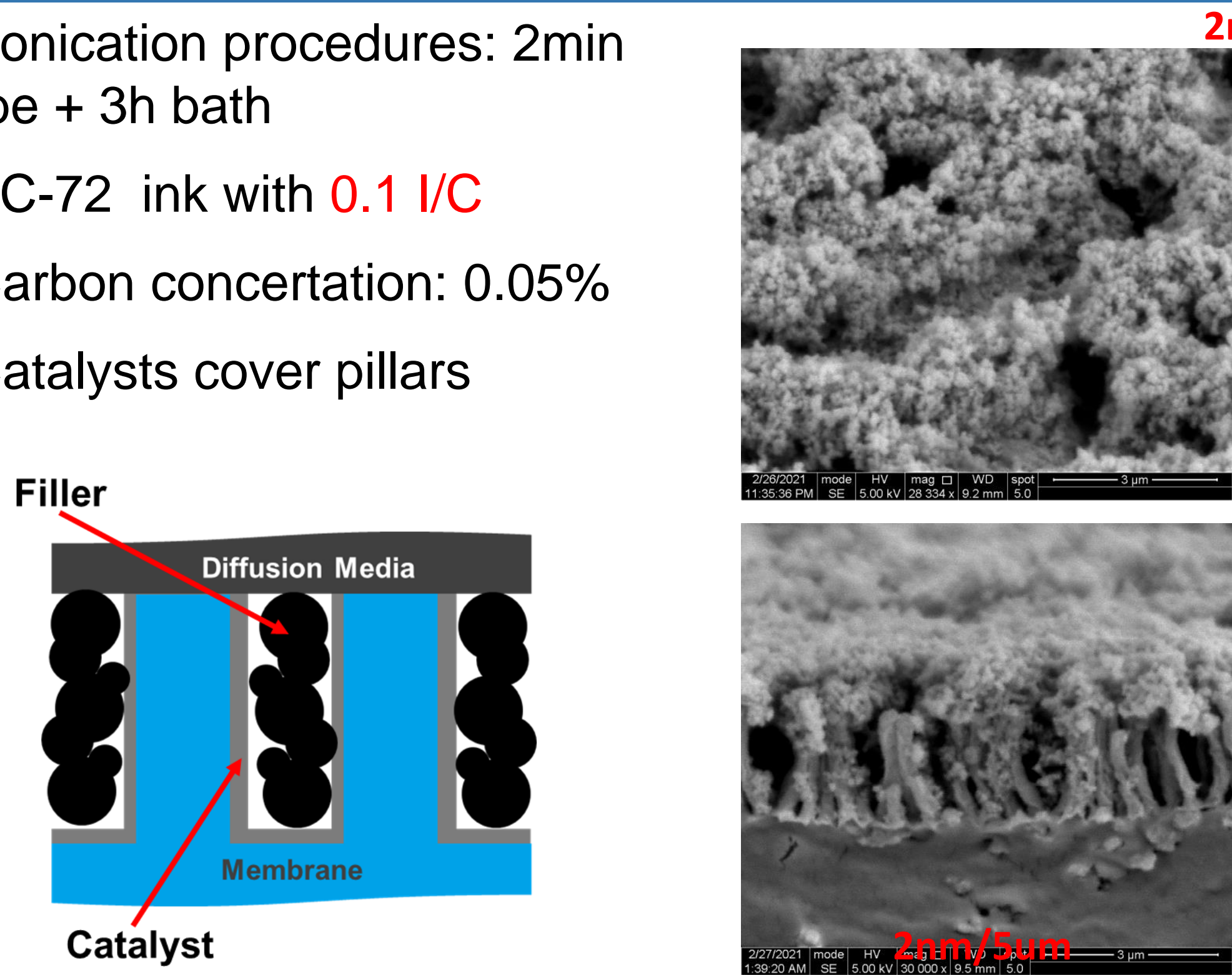

$2 \mathrm{~nm} / 2.5 \mathrm{um}$
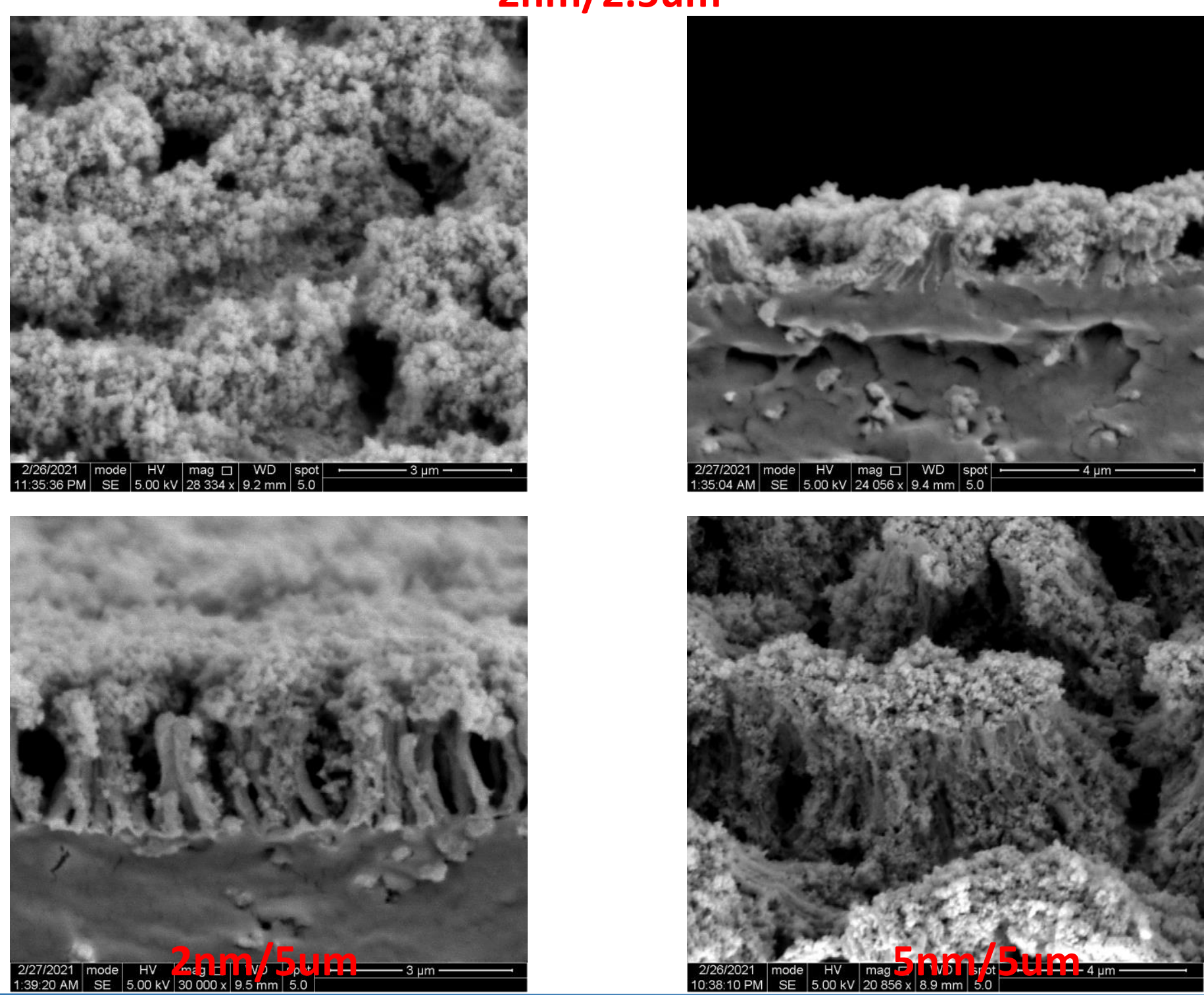
- Enhancing the strength of the pillar

- Preventing pillar collaps

Cross Pattern

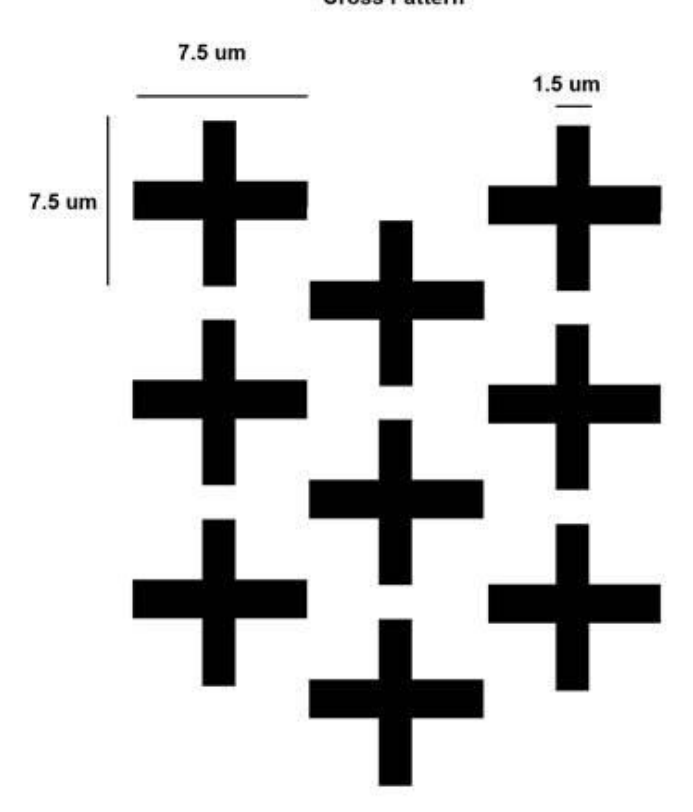

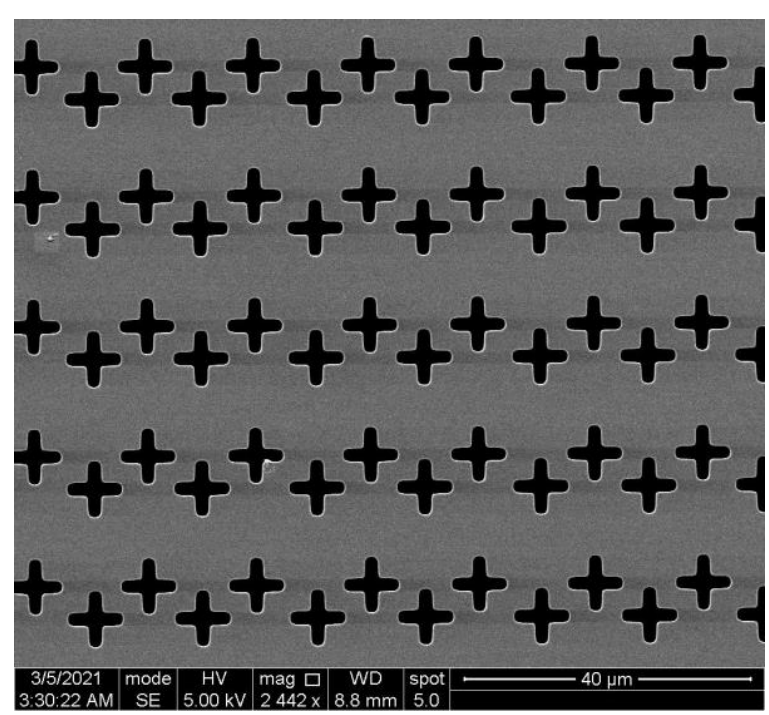

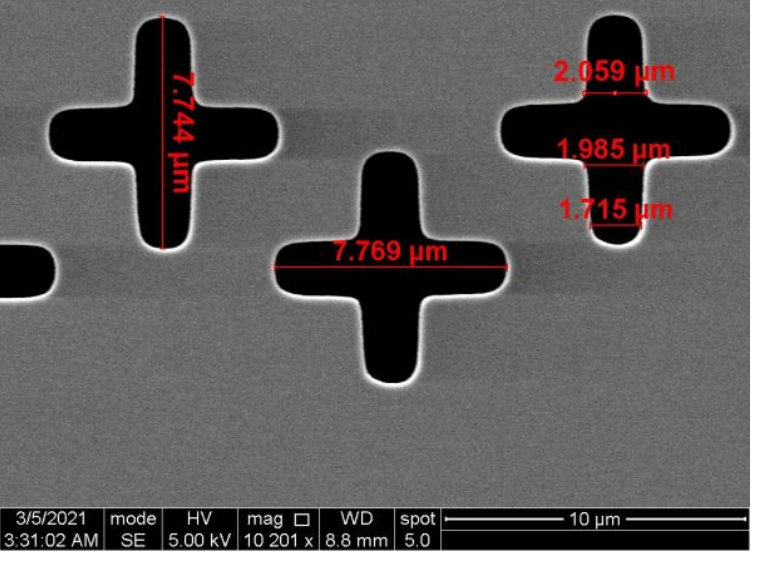

(1) I I

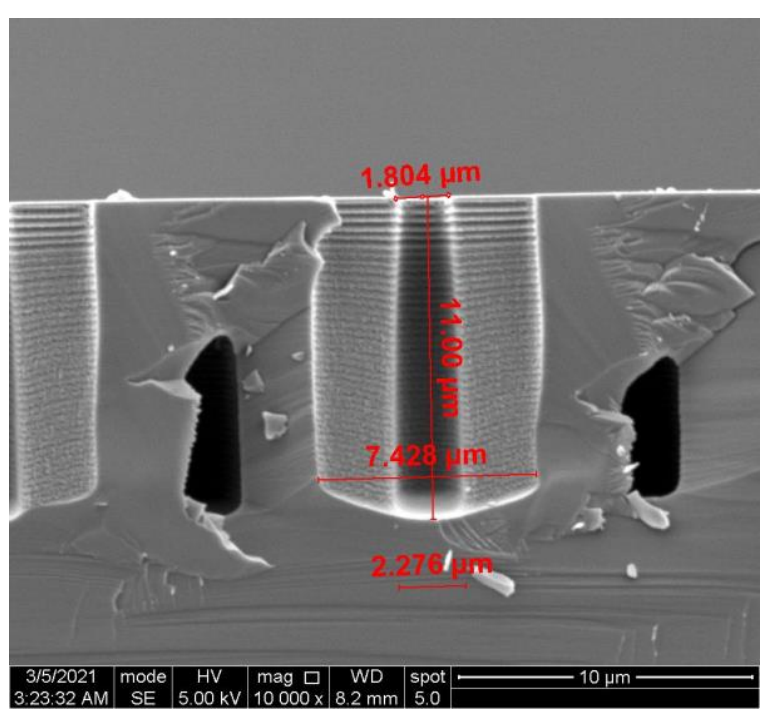




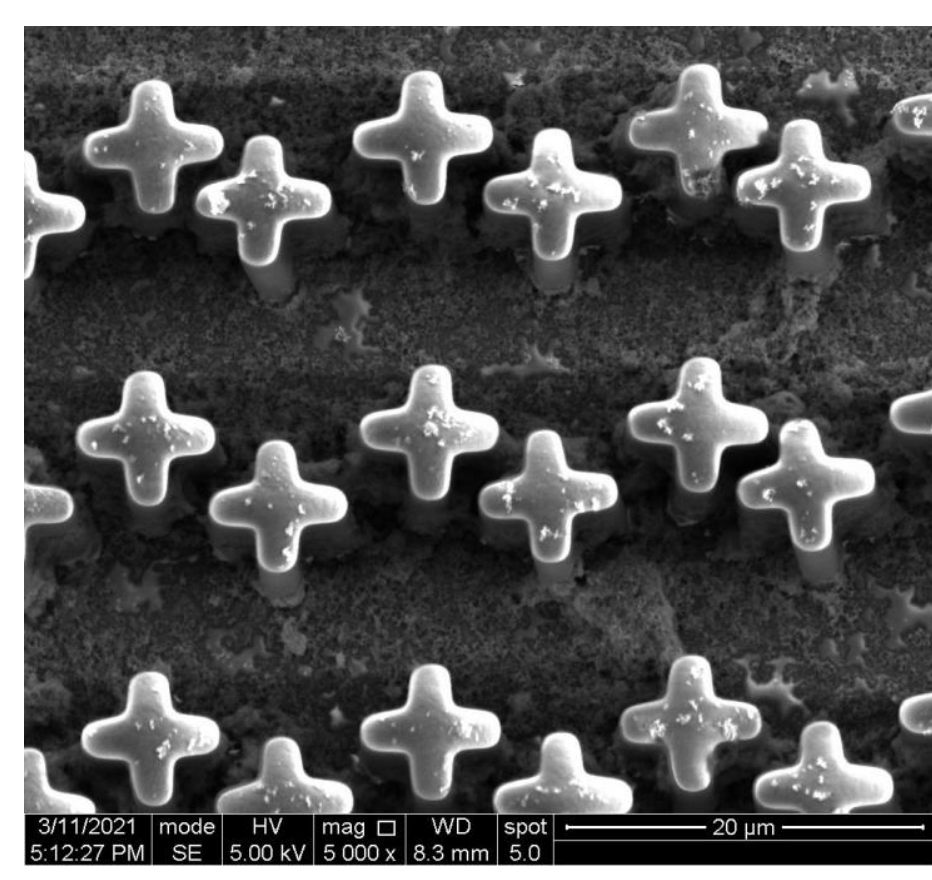

$23 \mathrm{ug} / \mathrm{cm}^{2}$ loading

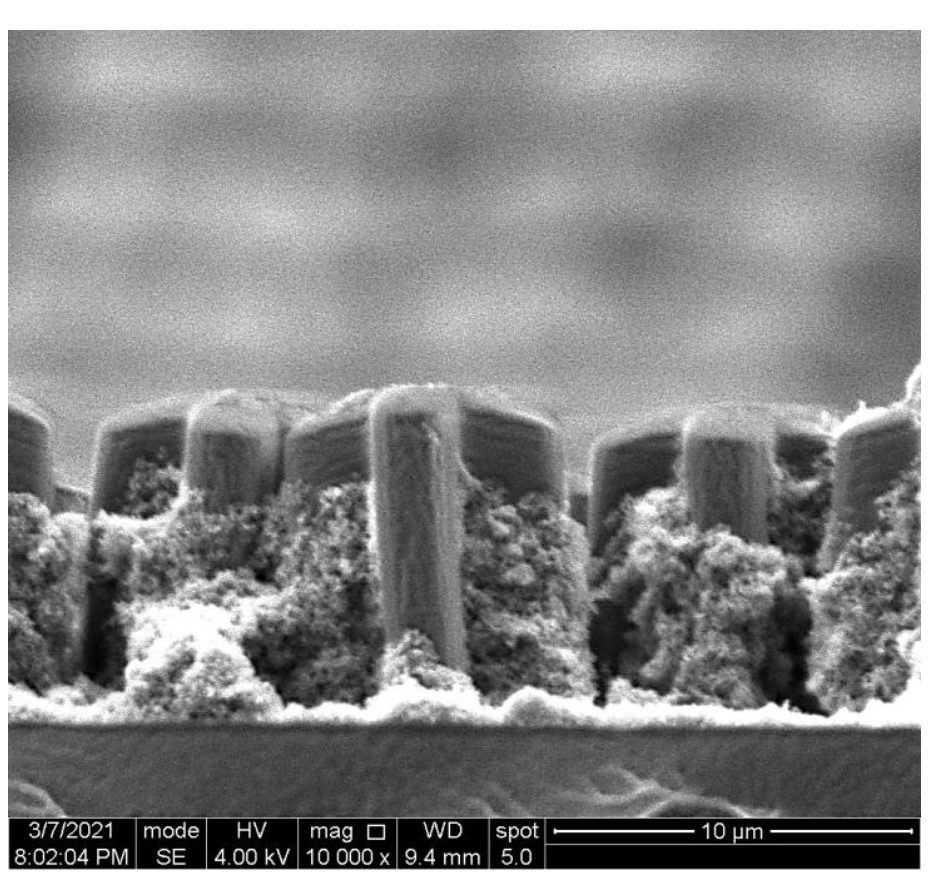

$45 \mathrm{ug} / \mathrm{cm}^{2}$ loading

- Different loadings

- No severe collapse is found.

- Catalysts were deposited on the surface 
Reasoning for inverse pillars:

- Better mechanical strength

- Prevention of pillar collapse

\section{Regular Si template with arrayed holes}
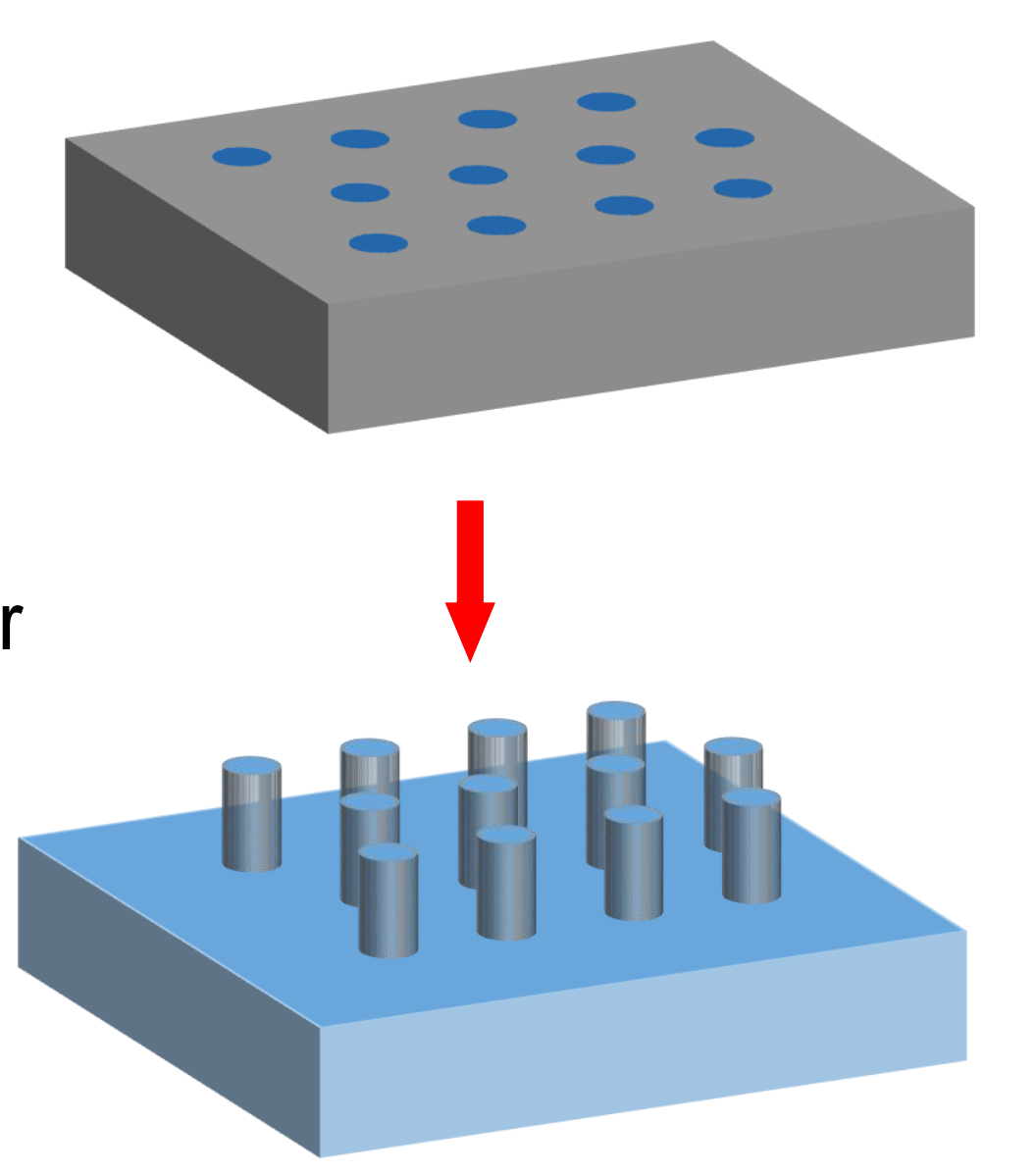

Patterned membrane with pillars
Inverse Si template with arrayed pillars

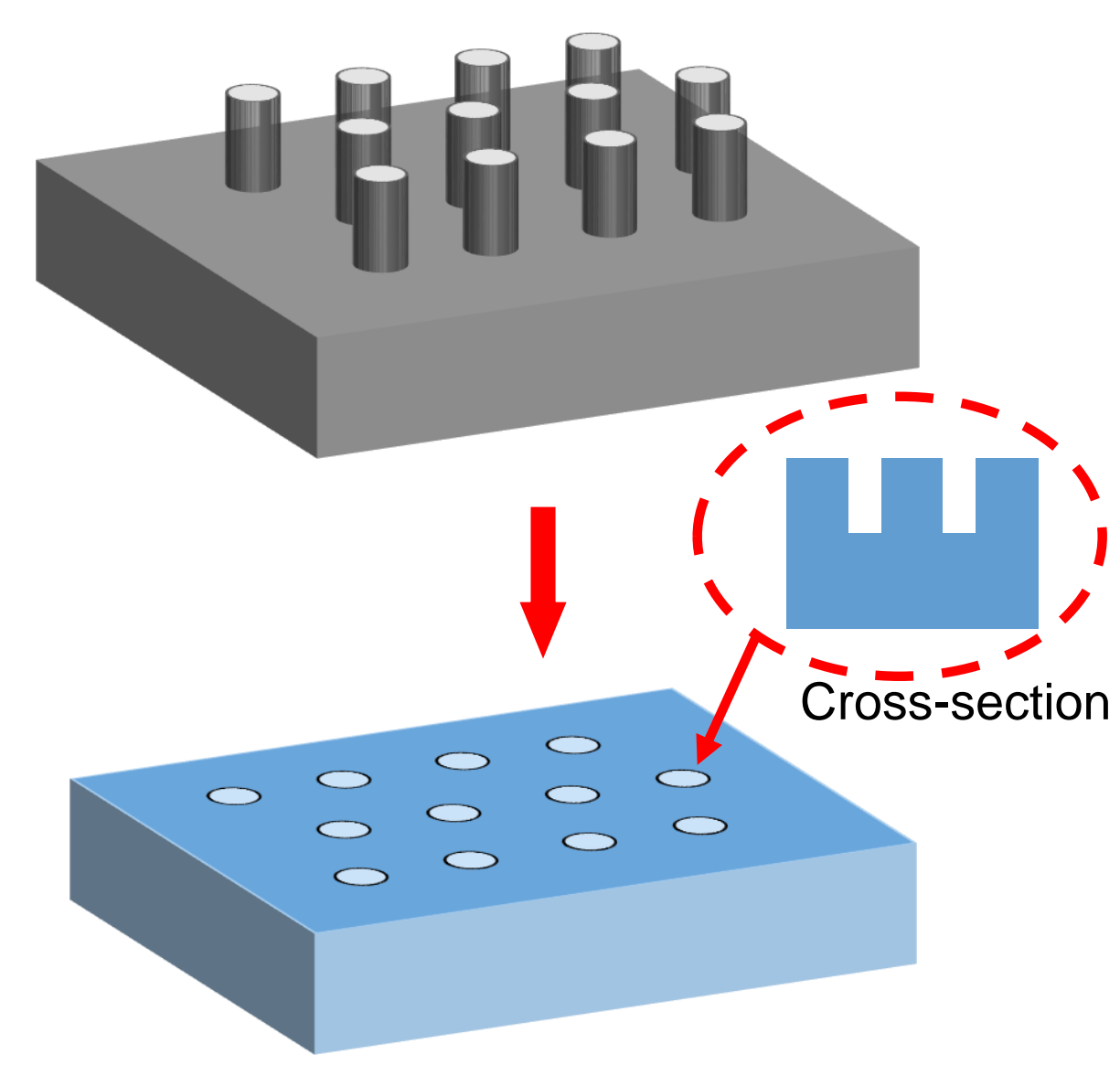

Patterned membrane with inverse pillars 
Inverse Array Electrode
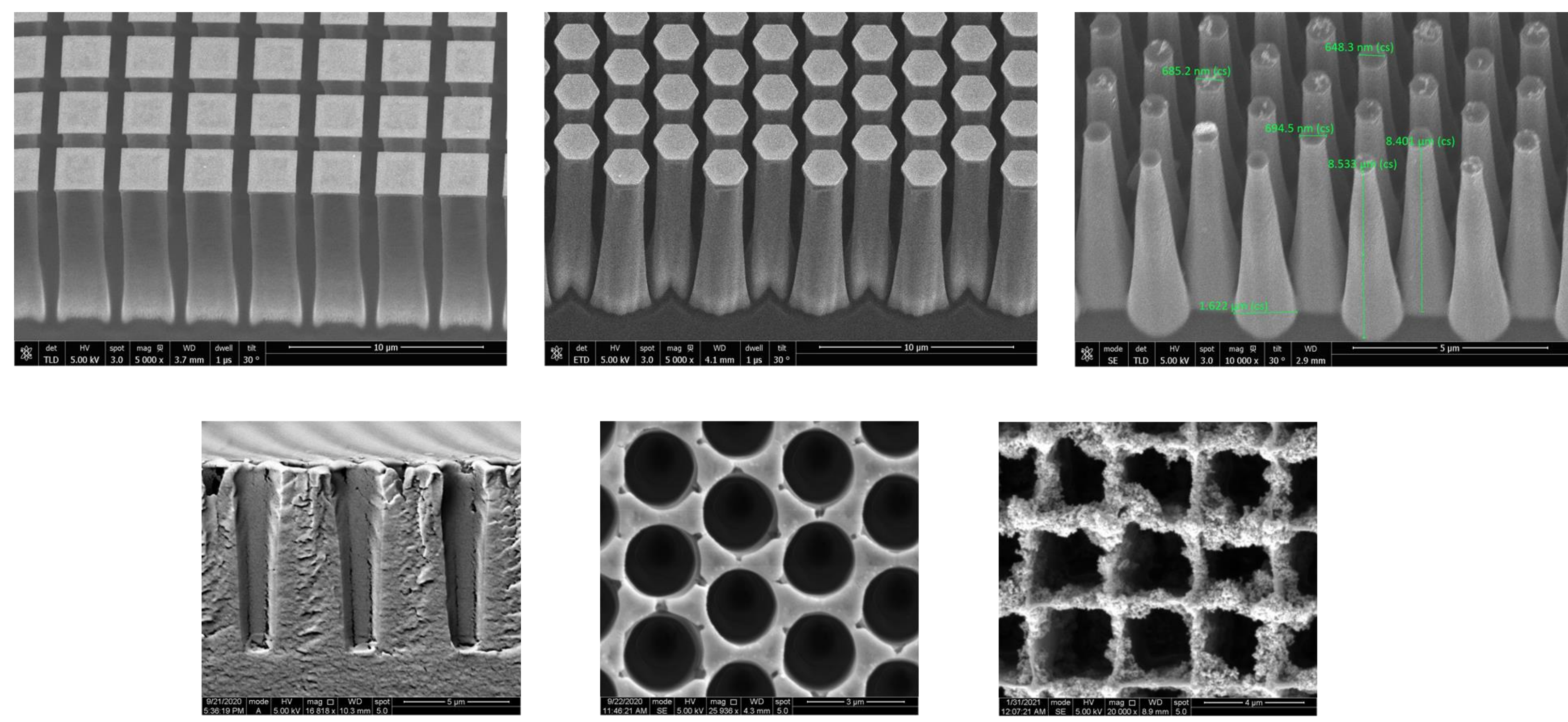


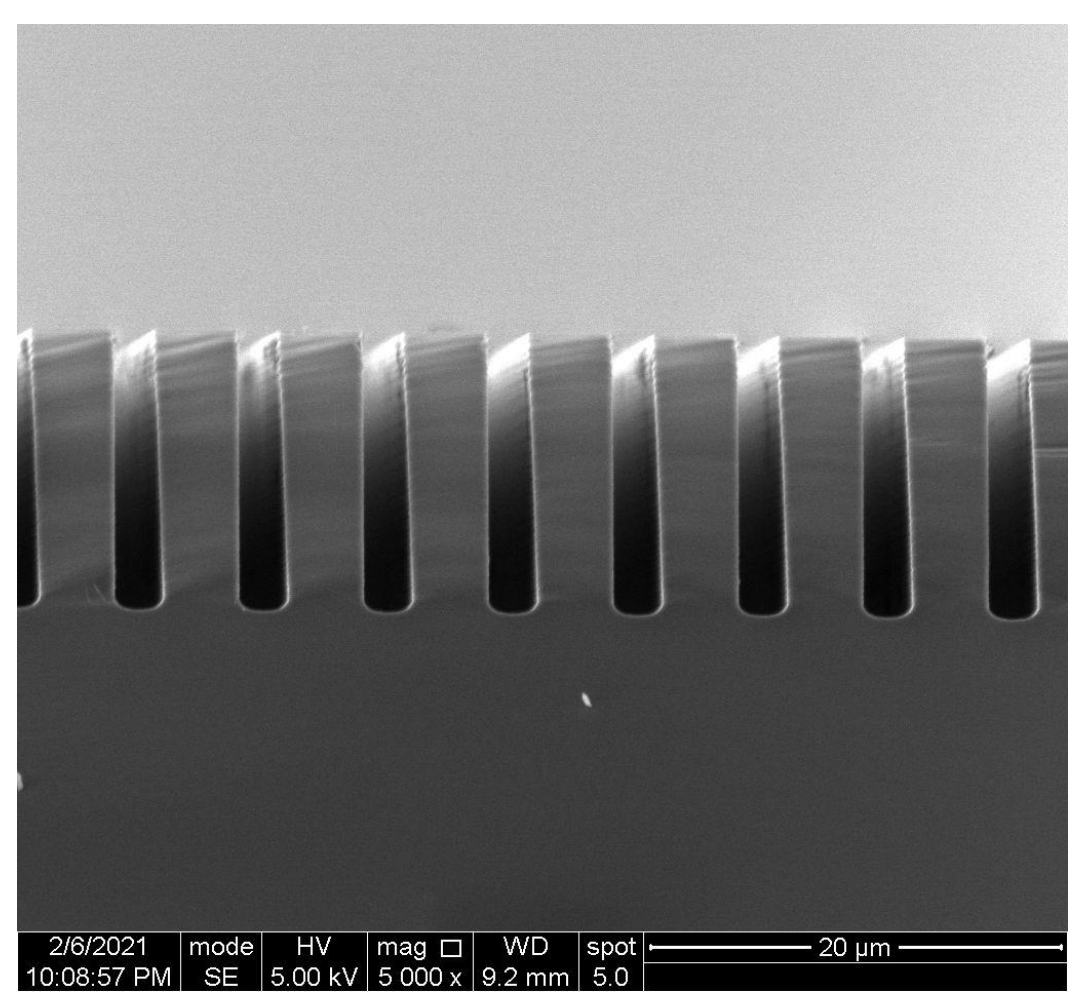

Si template with ridge
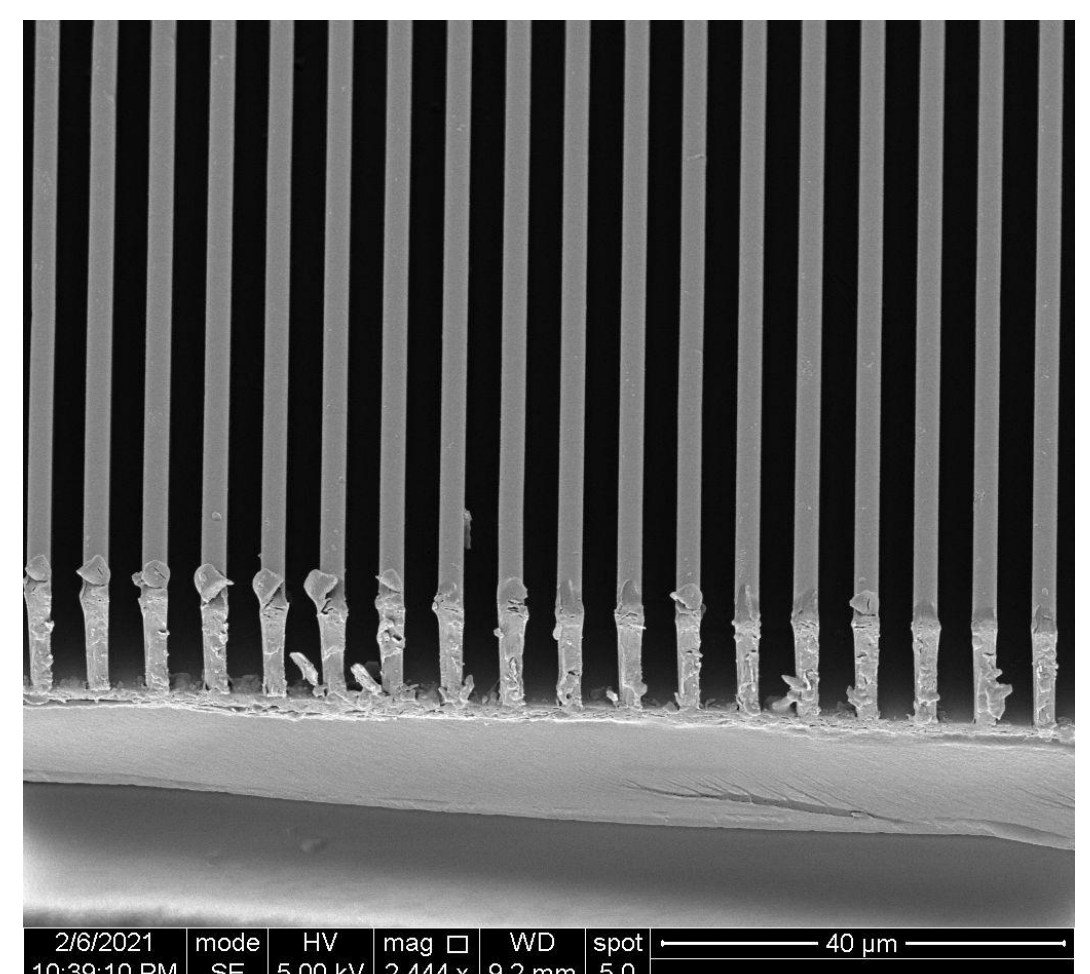

Nafion ridge

- Ridge width: 4.1 um/3.7 um

- Gap width: 2.0um/2.5um

- Ridge height: 13.4 um 